\title{
A perfect end: A study of syllable codas in South African Sign Language*
}

\author{
Mikhaela D. K. Köhlo, Ian Siebörger and William G. Bennett \\ Department of English Language and Linguistics, Rhodes University, South Africa \\ E-mail: mikhaelakohlo@yahoo.com; ian.sieborger@ru.ac.za; w.bennett@ru.ac.za
}

\begin{abstract}
South African Sign Language (SASL) is an understudied language with a rich and interesting phonology. For instance, while the language allows onsetless syllables, it does not allow codaless syllables, except in a small class of signs which do not include path movement. This article identifies and defines possible constraints on syllable codas in SASL. Using a video dictionary as data, we have coded handshapes at locations occurring at the onset and coda of the more common signs in the lexicon. In handshape, it has been found that the selected fingers may move to create different handshapes in the coda position, but that these coda handshapes are often [1], [5], [A], [̊̊] or [S], which are the unmarked handshapes of the nondominant hand in asymmetrical two-handed signs (Sandler and Lillo-Martin 2006). Furthermore, the joint specification for the selected fingers can also vary in the coda position, but there appear to be strict limitations on which joint combinations are permitted in the onset-coda relationship. There are also constraints on coda location. The major body region can change within a single syllable, and the preferred body regions in the coda position are [body] and [H2]. It is evident not only that handshape and location constraints occur at the coda position, but that these constraints show patterns similar to coda neutralisation in many spoken languages.
\end{abstract}

Keywords: South African Sign Language, phonology, Prosodic Model, syllable structure, codas

\section{Introduction}

This article explores constraints on codas in the syllable structure of South African Sign Language (SASL). This topic arises from the combination of several relatively uncontroversial premises. Spoken languages commonly impose restrictions on codas

\footnotetext{
* For insightful comments and discussion, we want to thank Dr Soya Mori, Mr Mfundo Jakeni, and Ms Asanda Katshwa. A South African Sign Language Dictionary for Families with Young Deaf Children (SLED 2006) was used with permission as a data source in this research, and we thank Sign Language Education and Development (SLED) for this. SLED is not responsible for any of the conclusions of this study, and only the authors are responsible for any errors in transcription or description of the data.
} 
(Lombardi 1999; Spencer 1996; Schütz 1995, among others). Sign languages are also thought to have syllables. As such, we might reasonably expect that codas in signed languages would be subject to restrictions of the same calibre as those observed in spoken languages.

In spoken language, syllables consist of at most three components: onset, nucleus, and coda (Blevins 1995; Wilbur 2011; Zec 2007, among many others). Structure is normally imposed both within and across these units according to the sonority sequencing principle (see e.g. Zec 2007 and much previous work). The most sonorous part of a syllable is the nucleus, while the less sonorous parts are located in the margins before and after the nucleus - the onset and coda. Onsets and codas consist of consonants, and the nucleus is occupied by more sonorous sounds, prototypically vowels. This is shown in Figure 1.

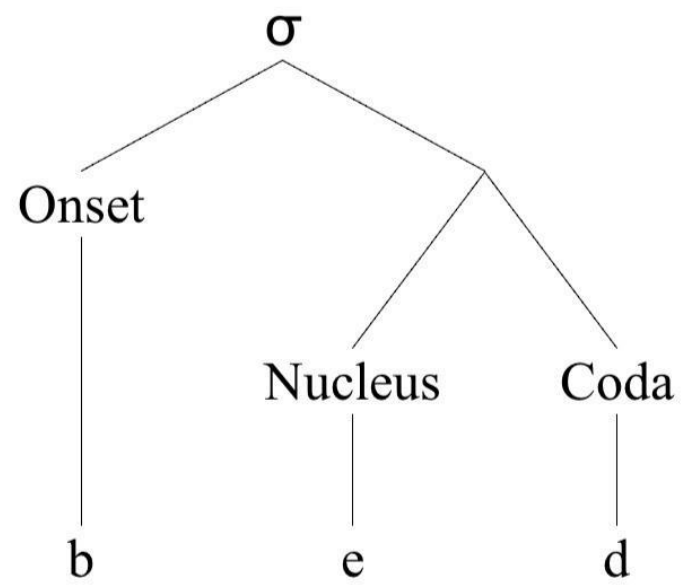

Figure 1: Syllable structure of a CVC syllable in the word "bed"

In spoken languages, syllable systems provide robust evidence for phonotactic restrictions and constraints. In particular, most of these restrictions exhibit an asymmetry between the two sides of a syllable nucleus: codas are generally more restricted than onsets (Blevins 1995; Fudge 1999; Kessler and Treiman 1997). This is evident in many languages. German, for instance, only permits voiceless obstruents in the coda position - all voiced obstruents go through syllable-final devoicing (Lombardi 1999; Wetzels and Mascaró 2001:208):

$$
\begin{array}{ll}
\text { a. } & \text { ei[z]ig 'icy' } \rightarrow \text { Ei }[\mathrm{s}] \text { 'ice' } \rightarrow \text { Ei[sb]är 'polar bear' } \\
\text { b. } & \text { wei[s]er 'whiter' } \rightarrow \text { Wei[s] 'white' } \rightarrow \text { Wei[sb]ier 'wheat beer' }
\end{array}
$$

Another such example - and one that is of direct interest to our research - is the phenomenon of debuccalisation in certain Malay dialects (Humbert 1995). In these dialects, /p, t, k/ and /s, f/ are not permitted in the coda position. When these phonemes appear on the underlying level, they are moved to [?] for stops and [h] for fricatives.

$$
\text { likat/ } \rightarrow \text { [ika?] 'to die' /lipas/ } \rightarrow \text { [lipah] }
$$

In addition, an abundance of languages require onsets, and some, such as Hawaiian, prohibit codas entirely (Blevins 1995; Schütz 1995:7-8): 
(3)
a. ono 'six'
b. $\quad$ kamali ' $i$ 'child'
c. $\quad p \bar{o}$ 'night'

A substantial body of work supports the claim that signed languages also have syllables (Liddell 1984; Sandler 1989; Perlmutter 1992; Brentari 1998; Newkirk 1998; Wilbur 2011). With the introduction of the Movement-Hold Model (Liddell and Johnson 1989; Johnson and Liddell 2010), signs were recognised as having a simultaneous and sequential structure. This model is the origin of the parsing of signs into static (consonant-like) components and dynamic (vowel-like) ones, as shown in Figure 2. The concept of separating a sign into its dynamic and static components became beneficial when looking at the concept of sonority in sign, a necessary component of the argument for the existence of the sign syllable (Wilbur 2011). It is this sequential division into C-like and V-like segments that we adopt from Liddell and Johnson (1989) and Johnson and Liddell (2010).

Studies on the sequentiality of sign languages have found that movements (M), much like syllable nuclei, are an obligatory part of a sign. It has been shown that if a sign in Italian Sign Language (LIS) has no movement at the underlying level, movement is inserted - a phenomenon called movement epenthesis - on the sign's surface level (Sandler and LilloMartin 2006; Geraci 2009). This is similar to the necessity of a sonorous peak in spoken syllables, as movements are also considered to be the most sonorous part of a sign (Sandler and Lillo-Martin 2006; Geraci 2009; and Wilbur 2011). Furthermore, these sonorous peaks are flanked by holds $(\mathrm{H})$, which are thus comparable to consonants, as shown below. Thus, the hold before a movement is an onset, and the hold following a movement is a coda, making up a sign language syllable, as shown in Figure 2. We follow Liddell and Johnson (1989) in postulating that the initial and final segments of syllables constitute individual timing units, and so refer to them as 'holds' rather than referring to them as 'locations', as Sandler and Lillo-Martin (2001, 2006) and Perlmutter (1992) do.

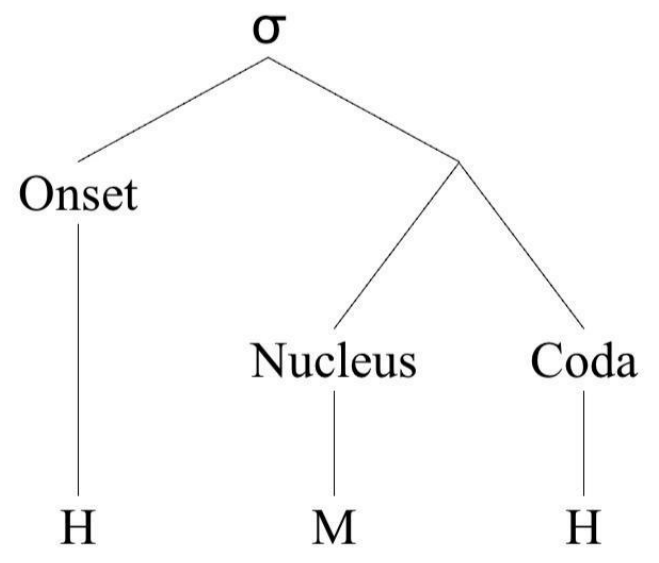

Figure 2: The structure of a sign language syllable

Sign language syllables are defined by the presence of movement - that is, one movement is equated to one syllable. Therefore, the static states on either side of this peak are considered to be the boundaries of a sign syllable. These syllable boundaries (onset and coda) are easily 
determined when signs are in isolation. In connected signing, it is possible that these constraints will interact in an interesting way. However, as this research is one of the first of its kind, this study will focus on signs in isolation, with the aim of laying the groundwork for additional research on connected signing. It is our opinion that the syllable should first be investigated in signs in citation form, so that we are able to determine the constraints on the syllable in isolation before exploring how these constraints interact in connected speech. It is important to mention, however, that some signs comprise multiple syllables. Here, the difference between the coda of one syllable and the onset of another is less distinct. The concept of 'ambisyllabicity' in multisyllabic SASL signs is discussed further below.

If the basic organisation of syllables (in terms of onset, nucleus, and coda) is the same across spoken and signed languages, it follows that we might expect to find constraints on what specifications are permitted for holds that occur in coda positions. In this paper, we argue that SASL provides evidence in support of this intuition.

The handshapes and locations that can be found in codas are a subset of those permitted in onsets. Additionally, we find in our data that SASL syllables which involve a change in location or handshape only utilise a subset of the possibilities that exist for codas. The set of handshape features permitted in the coda of a syllable is closely aligned with the set of handshapes found on the non-dominant hand in two-handed signs. This generalisation is strongly reminiscent of coda neutralisation processes well documented in the world's spoken languages, such as devoicing and debuccalisation (see Wetzels and Mascaró 2001; de Lacy 2006 for further details). Languages with coda devoicing have laryngeal feature contrasts, but use only a subset of the possible features in coda position - the subset that is least marked (i.e. voiceless, not voiced). In much the same way, SASL signs that change handshape use only a subset of handshapes in coda position - and this is the subset that is least marked, on the basis of independent evidence from the non-dominant hand.

\section{A brief overview of SASL}

Historically, SASL has been influenced by British Sign Language (BSL), American Sign Language (ASL), and Irish Sign Language (ISL) (Ngwinika 2016). During the $19^{\text {th }}$ century, Catholic nuns from the Irish Dominican Order and missionaries from the Dutch Reformed Church set up schools for the Deaf in South Africa (Storbeck 2010). Certain provinces were more strongly influenced by one particular sign language. For example, a British teacher influenced the signing taught at St Vincent School for the Deaf in Johannesburg, South Africa, resulting in BSL having more of an influence in what is now the Gauteng province than in other South African provinces. By contrast, Irish nuns ran the first school for the Deaf in the Western Cape, resulting in ISL having more of an influence in this province (Ngwinika 2016). German Dominican nuns who had come to South Africa brought German signs, a twohanded alphabet, and an emphasis on teaching via oral methods. While each school was influenced by the sign language of the school's founders, the oral teaching method - later known as "oralism" - later grew in popularity in schools across the country, as it was thought to encourage integration with hearing society (Storbeck 2010).

The first schools for the Deaf in South Africa did not have racial segregation (Storbeck 2010). Beginning in 1948, the law enforced the segregation of schoolchildren according to race. The racial segregation of Deaf schools was a steady process, which started before the apartheid 
laws were promulgated. The Dutch Reformed Church funded and established Nuwe Hoop - a Deaf school exclusively for coloured ${ }^{1}$ children - in 1933, and Khutlwanong - a black school for the Deaf - was established in 1941 (Akach, Demey, Matabane, Van Herreweghe and Vermeerbergen 2009; Storbeck 2010). ${ }^{2}$ Learners at white schools were instructed through oralism. Indian students were taught Signed Exact English. Black African schools primarily used manualism. This history of segregation has led to the existence of distinct 'black' and 'white' varieties of SASL. Because of this, questions have been raised as to whether there is one South African Sign Language or many, as based on race and regional differences (Akach et al. 2009). The general academic consensus is that there is one sign language in South Africa, albeit with varying levels of spoken language influence (Akach et al. 2009). As a result of the history of Deaf education, black signers are considered to have less spoken influence on their signing and are thus often preferred over white signers as informants (Ganiso and Kaschula 2013).

Deaf people in South Africa, who form the majority of SASL signers, are a highly marginalised community. At present, SASL is not one of the 11 official languages of the country. There are many reasons for this marginalisation, some of which are common to Deaf communities around the world, and some of which are particular to South Africa, given its history of racial discrimination. Firstly, most deaf children are born to hearing parents, meaning that they are only properly exposed to SASL when they enter a Deaf school (Akach et al. 2009). Another problem that arises is a family's potential bias against Deafness: more often than not, there is a societal emphasis on 'fixing' a child's deafness and attempting to teach deaf children to integrate socially with the hearing world, rather than fostering communication in SASL (Scott 2014). Many Deaf South Africans leave school unable to read or write, thus making it harder to integrate into society (Scott 2014). The skewed focus on integrating into hearing society was confirmed by one of our informants, who recounted being forced to sit on his hands during lessons. Fortunately, there have been many positive changes in the manner in which SASL and Deaf children are being dealt with in schools: there is more focus on training teachers of Deaf children and, in 2015, SASL was recognised as an official school subject for the first time. Morgan, Glaser and Magongwa (2016) describe the process leading up to the construction of the new SASL curriculum and examine the many obstacles that hindered it, particularly the widespread ignorance among hearing South Africans about SASL and Deaf people's linguistic rights.

The few previous studies on the linguistics of SASL have focused mainly on the morphological, syntactic, and sociolinguistic aspects of the language. For example, Aarons and Morgan (2003) have researched the nature of classifier constructions in SASL and their role in syntax as well as in discourse genres such as storytelling. Vermeerbergen, van Herreweghe, Akach and Matabane (2007) have compared Flemish Sign Language (VGT) word order with that of SASL, finding that SASL has strictly a verb-final word order. However, there is little research on the phonological nature of SASL.

\footnotetext{
${ }^{1}$ In this article we use terms referring to 'race' which are in common usage in present-day South Africa. "Coloured" refers to people of mixed European, Asian, and African descent. "Black African" refers to Bantulanguage-speaking people of African descent, "white" refers to people of European descent, and "Indian" refers to people descended from the Indian subcontinent. Following common academic usage, we use "black" to refer collectively to 'black African', 'Coloured', and 'Indian' people.

${ }^{2}$ When the Dutch Reformed Church managed these schools, Afrikaans rather than Dutch was the main language of the church, and there is no evidence of influence from Dutch Sign Language (NGT) on these schools.
} 
While there has been a steady stream of research on the phonological nature of sign languages, most of these studies centre on sign languages of the West. The phonological systems of African signed languages, including SASL, have largely not been studied, and this paper is one of the first formal studies of any aspect of SASL phonology known to the authors.

SASL is a vastly understudied language, which could potentially contribute to linguistic theory. Thus, research about this sign language not only benefits the community that uses it, but contributes to the study of sign languages as a whole.

\section{Methodology}

As this study is one of the first of its kind, it was preferable to select data that would reveal the most basic of patterns in order to lay a foundation for future research. Thus, we used $A$ South African Sign Language Dictionary for Families with Young Deaf Children, a dictionary designed by Sign Language Education and Development (SLED), a non-governmental organisation situated in Johannesburg, Gauteng province and Cape Town, Western Cape province (SLED 2006). The dictionary is a booklet with a vocabulary of 153 signs, giving a headword and an example sentence for each. As such, the dictionary is small in scope, with a focus on simpler signs. Given the corporal-visual nature of sign language, the dictionary includes a DVD that shows the way in which the signs are to be articulated. This DVD is the primary source of our data. The signer recorded in the DVD is a black Deaf woman who has worked extensively with SLED and has been involved in the teaching of SASL to hearing people. As the organisation is divided between two different provinces in the country, it can be assumed that the signer is using either the Johannesburg or Cape Town variants of signs. In choosing variants for inclusion in the dictionary, the compilers stated that they selected those that were most widely understood across different regions, and that more iconic variants were preferred (SLED 2006). According to Aarons and Reynolds (2003), signers from various different regions can understand one another's variants with little difficulty. While we are uncertain of how the signs were elicited, SLED's staff are predominantly Deaf, and so it is probable that there was very little hearing influence in the production of this video dictionary. While such a small dataset would not be preferable for further studies on the complexities of signs as used by signers, the data are sufficient for an initial analysis. The handshapes and locations found in all 153 signs are the most common ones, providing an adequate basis for a first analysis of constraints on SASL syllable codas.

There is a much more comprehensive dictionary of SASL, the five-volume Dictionary of Southern African Signs for Communicating with the Deaf (Penn 1992). This dictionary, however, does not have a video element, but only photographs depicting the articulation of each sign. Such photographs are not capable of accurately depicting the movement of a sign, which is a crucial element of a sign's articulation. It is possible that certain aspects of articulation may be overlooked or missed without the aid of video data; thus, this dictionary would not have been a suitable data source for this research.

In our research, we consulted two informants - both members of the South African Deaf community - who helped us to clarify syllable boundaries. After our proposed constraints on codas were formulated, we tested them with one informant to determine which constraints were legitimate and which were a result of a gap in the dictionary data. 
Informant $\mathrm{A}$ is a black African woman who was born in East London in the Eastern Cape province, but has lived in three different provinces throughout her life. Although she is hearing, she is born from Deaf parents and has SASL as her first and native language. She obtained both a university diploma and a BA Hons from the University of the Witwatersrand, specialising in sign language interpretation and translation. She is an active member within the Deaf community and works with Deaf individuals as an interpreter and as a teacher to SASL interpreters. As a result of her work as a sign language interpreter, she has worked in Sweden, Spain, Swaziland, Nigeria, Mauritius, and Botswana.

Informant B is a black African man who was born in the Eastern Cape. He was born fully Deaf and attended a school for the Deaf in King William's Town in the Eastern Cape. He is an active member of the Deaf community. Additionally, he worked as a sign language teacher and a representative of the Deaf Federation of South Africa (DeafSA). As part of his work, he has travelled extensively throughout South Africa and is familiar with the different dialects of SASL.

These informants thus represent two different kinds of native signer and were able to provide native signer intuitions, including negative evidence, when testing our constraints. They also provided syllables that were not present in the SLED (2006) dictionary, but were counterexamples to our putative constraints.

The first thing we consulted our informants for was confirmation of the phonotactic rules of syllable boundaries. During a face-to-face interview, the first author initially signed selected words to the informants from various starting positions and asked them to offer judgements on the well-formedness of each sign. Then the first author asked Informant A in English for her and Informant B to sign the same signs from places that felt most natural to them. Informant A relayed this information to Informant B and they discussed among themselves before articulating the signs. A similar method was used to ascertain whether a coda was compulsory in a selected sign.

Following our analysis, the first author conducted an interview with Informant A over Skype to confirm the validity of the constraints on syllable codas presented in this article. In this interview, she signed a series of hypothetical nonce-signs that violate these constraints and, after each one, asked Informant A if such a sign would be possible in SASL. She also asked Informant A if she could think of any signs similar to these nonce-signs in coda handshape or location. Using this method, we were able to elicit counterexamples to some of our putative constraints and confirm that other constraints were indeed applicable to the phonology of lexical signs in the language as a whole.

An additional concern with the SLED (2006) dictionary as a data source is that the dictionary is intended for parents of Deaf children and for Deaf children themselves, which could influence the way the signs are articulated. It could be argued that the nature of the dictionary would mean that the signer being filmed is hyperarticulating to make learning SASL easier. However, when our informants signed the same signs when we elicited them in the interview process, we discovered that there was little qualitative difference between their articulation of the signs and that found in the dictionary. Citation signs in the dictionary are articulated more slowly than would be natural in connected signing and movements may also have been exaggerated in places, but the main parameters we were concerned with, namely locations and 
handshapes at onsets and codas, were largely similar to those used by our informants. This also demonstrates the wide currency of the variants used in the dictionary: our informants were familiar with the dictionary variants in all but one case.

Using the feature theory developed from Brentari (1998), the handshape and location features of each dictionary headword at the onset and coda positions were coded in a database. ${ }^{3} \mathrm{We}$ restricted the scope of our investigation to citation forms of headwords, and left for future work the analysis of any phonological processes that may occur in connected signing.

The database allowed us to make note of patterns in both major class features (or primary features) and secondary features. Patterns noted in the database were analysed and compared to similar patterns found in research on other sign languages and conclusions were drawn regarding the state of the coda.

After using the dictionary to note the features occurring at onset and coda, we focused on patterns of handshape and location features specified at the onset and the coda of each syllable. Of particular interest were syllables where the onset handshape and/or location differed from that of the coda. Once patterns were noted, we compared these to patterns found in the literature on both spoken and sign syllables and formulated putative constraints on syllable codas in SASL.

It should be noted that certain signs in the SLED (2006) dictionary were not considered as data. These include signs that only had secondary or local movement at the syllable nucleus (as these do not have onsets or codas), had circular movement (as the onset and coda are identical in these instances), or appeared to be lexicalised classifier constructions (which are more iconic and so follow a different set of phonological rules to the rest of the SASL lexicon). Repeated signs (i.e. signs where a syllable is repeated for well-formedness) were analysed as monosyllabic, following Geraci's (2009) conclusion that because these signs consist of the repetition of a segment, only the first syllable of the sign counts as a timing slot; the movement from the coda location of the first syllable back to the onset location does not count as a timing slot.

\section{The phonological structure of SASL}

As stated in the introduction, sign syllables have been found to consist of an onset, a nucleus, and a coda. The phonological structure of SASL is quite similar to that of other sign languages that have been investigated. Most words consist of only monosyllabic free morphemes that can be described using the parameters specified in most current models of sign language phonology, including handshape, orientation, location, movement, and nonmanual features. Disyllabic and polysyllabic signs are found, although these are in the minority. SASL also has many instances of what we label "repeated signs", in which a single syllable must be repeated at least once in order for the word to be well-formed. A transitional movement is inserted into these repeated signs to allow the hand to move from the coda location of the syllable back to the onset location in order for the syllable to be repeated. In addition to lexical signs, SASL makes extensive use of classifier constructions

\footnotetext{
${ }^{3}$ We also coded for the number of hands used, the part of speech of each sign, and the extent to which the sign was visually iconic or opaque.
} 
(Vermeerbergen et al. 2007), which do not conform to the same phonological rules as lexical signs. In this article, we concentrate on the phonology of lexical signs.

In terms of the structure of SASL syllables, evidence from our dataset (described in section 3) suggests that location does not need to be specified in the onset position for all signs. Such a situation can be found in signs such as YEAR, DANGEROUS, and COW, shown in Figure 3. In each of these signs, the movement starts from the resting position; there is no set or distinct location at the beginning of the sign.

Our native signer informants confirm that this is the case according to their intuitions. In an interview, we asked our informants to articulate these signs slowly and to try to identify their initial handshapes and locations. It was found that in citation form, these signs originated from what is known as "at rest" (Brentari 1998), i.e. the most neutral place from which a sign can begin. As the resting place is not specified for any articulation features, it is assumed that there is no initial location or handshape, much like how spoken articulators are not specified when not articulating. Figure 3 depicts the movement from the resting position.
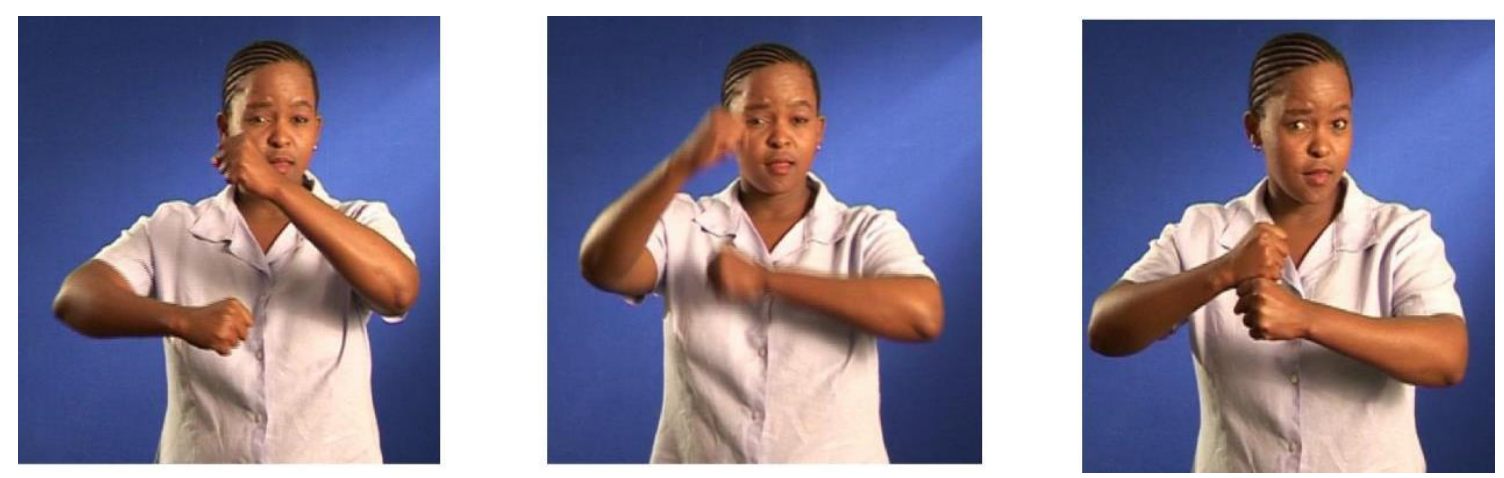

Figure 3a: YEAR (SLED 2006)
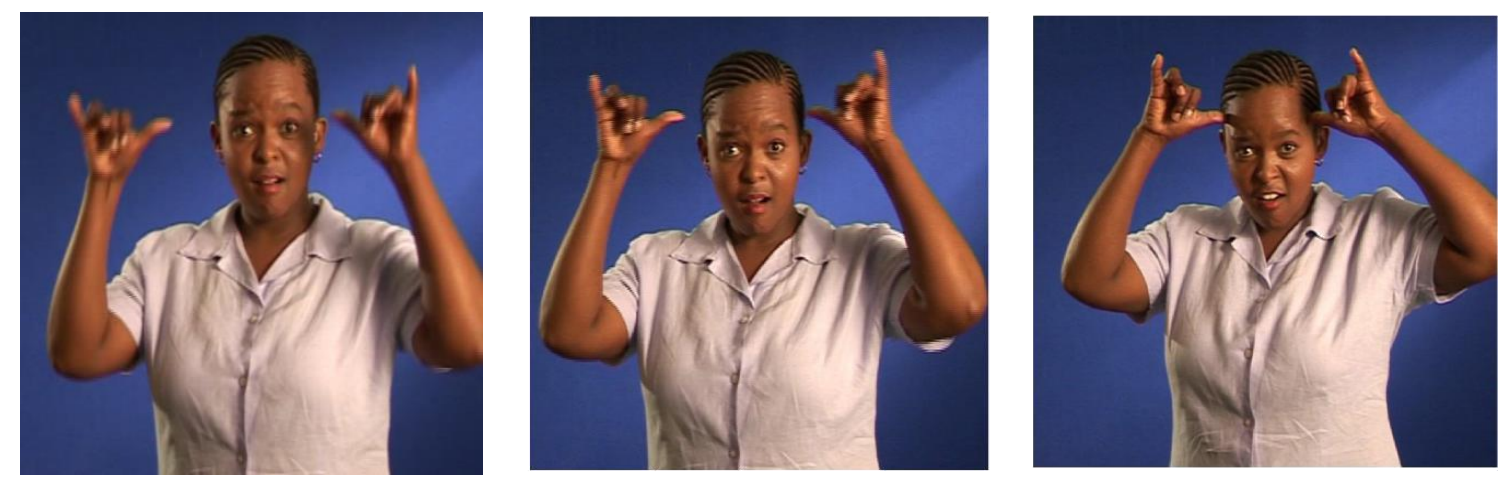

Figure 3b: COW (SLED 2006)

The following featural descriptions of the signs show the onset and coda handshapes and locations, with handshape being described first and location second. In both YEAR and $\mathrm{COW}$, the lack of onset location is marked using "[Ø]".
a. $\quad$ YEAR: [S]-[Ø] $\rightarrow[\mathrm{S}]-[\mathrm{H} 2: 5]$
b. $\quad$ COW: $[\mathrm{Y}]-[\varnothing] \rightarrow[\mathrm{Y}]-[$ head:2] 
It seems that handshapes too may be unspecified in the onset position. Potential examples of this are the signs SOUR and ORANGE (Figures 5a and 5b), as well as OWL. The handshapes for these signs are unspecified until they come into contact with the signer in the coda position. This phenomenon was also confirmed by our informants, who noted that there is no distinct handshape at the beginning of the sign.

It should be noted that in the Prosodic Model (Brentari 1998:26), orientation is the combination of handshape and location (also known as "place of articulation" (POA)). Therefore, if handshape and location are not specified at the beginning of a sign, the orientation is also unspecified at the beginning of a sign. This is shown in Figure 4:

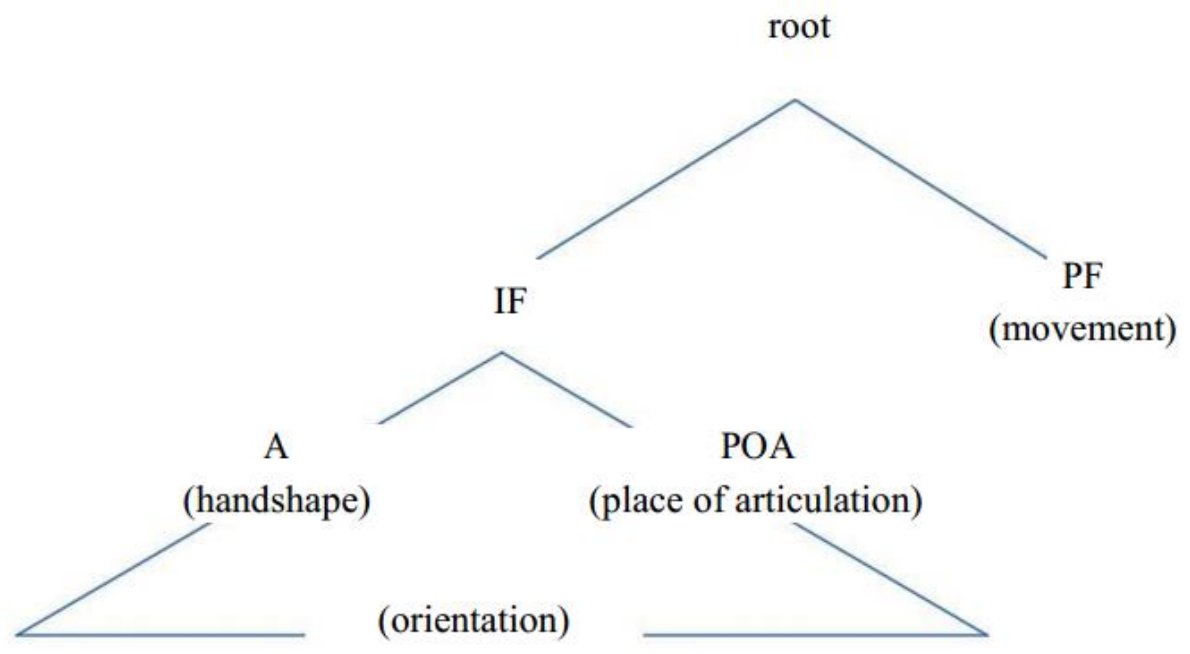

Figure 4: The placement of parameters in the Prosodic Model (Brentari 1998:26)

However, from the data provided, it has been found that onsets that do not have specified handshapes are rare. In cases where the handshape is unspecified, the hand comes from a resting/neutral position. Example signs are provided below. In Figure 5a, we see an unspecified handshape at the start of the sign changing to a [3] specification with the sign SOUR. Figure $5 b$ shows an unspecified handshape changing into [S] in the sign ORANGE. It is difficult to illustrate using pictures what an unspecified handshape may look like, as every given articulation of the sign will have one handshape or another at the syllable's onset; however, our informants have confirmed that the onset handshape for SOUR can differ significantly from one articulation to another, and so is not lexically specified. 

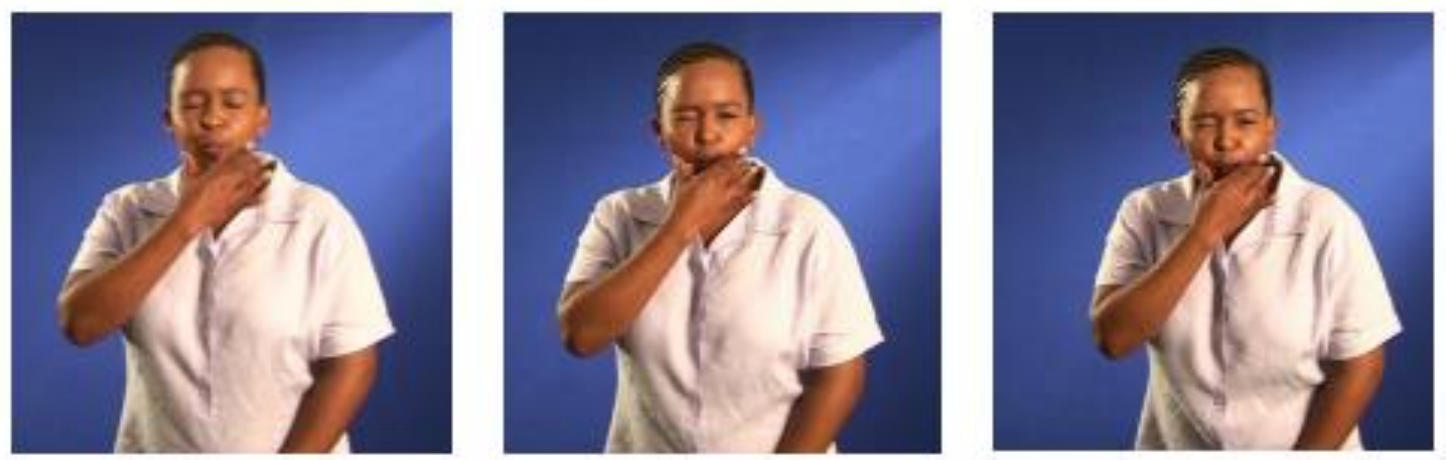

Figure 5a: $[\varnothing] \rightarrow[3]$ in SOUR (SLED 2006)
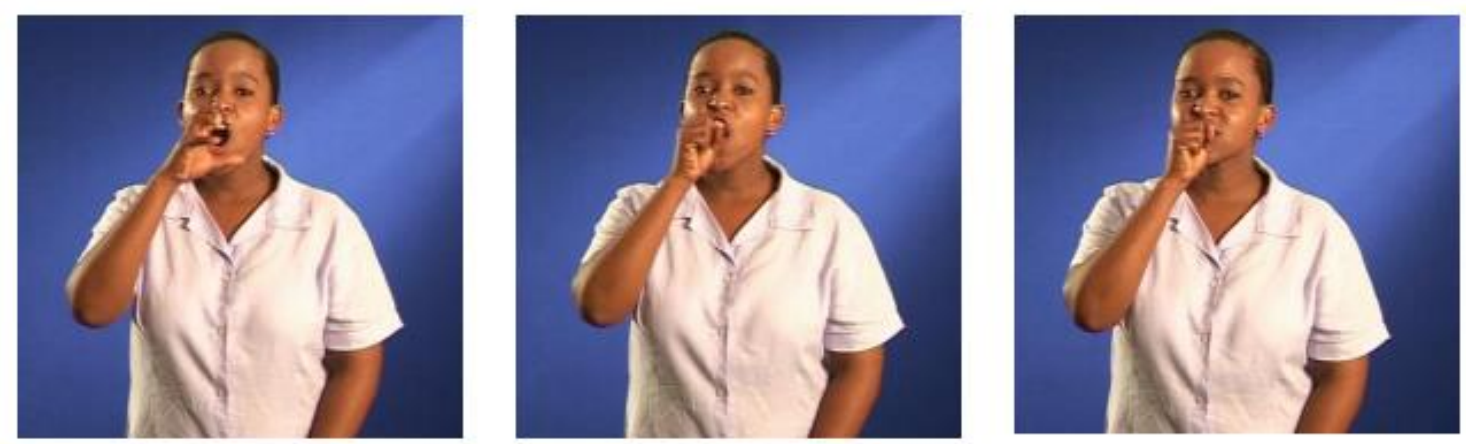

Figure 5b: $[\varnothing] \rightarrow[S]$ in ORANGE (SLED 2006)

Featural descriptions of the aforementioned signs' handshapes and locations are given below:

$$
\begin{array}{ll}
\text { a. } & \text { SOUR: }[\varnothing]-[\varnothing] \rightarrow[\text { thumb],[2]-[head:4] } \\
\text { b. } & \text { ORANGE: }[\varnothing]-[\varnothing] \rightarrow[\text { S]-[head:6],[proximal }]
\end{array}
$$

In the instances where the handshape is not specified, the location is also not specified. We interpret such signs as having onsetless syllables, consisting only of a movement and then a hold in the coda. All of the onsetless signs in our small SASL dataset consist of only one syllable. This suggests that in multisyllabic signs, it may be compulsory for the handshape to be specified; a pattern that does not obviously mirror any well-established property of spoken language syllables.

While multisyllabic signs in our dataset are never onsetless through omission of both handshape and location, the location in a multisyllabic sign can be unspecified, but only in the sign's first syllable. This is seen in the sign for DOG in Figure 6. In this sign, the first syllable does not have a location specified at the onset (first frame): it is grammatical to begin the sign from the resting position. However, the coda of the first syllable (second frame) and the onset (third frame) and coda (fourth frame) of the second syllable have specified locations. The second syllable consists of a click of the fingers. While the first syllable's onset does not have location specified, the second onset is the same as the coda for the first syllable. This illustrates that handshape and location features are often ambisyllabic. 

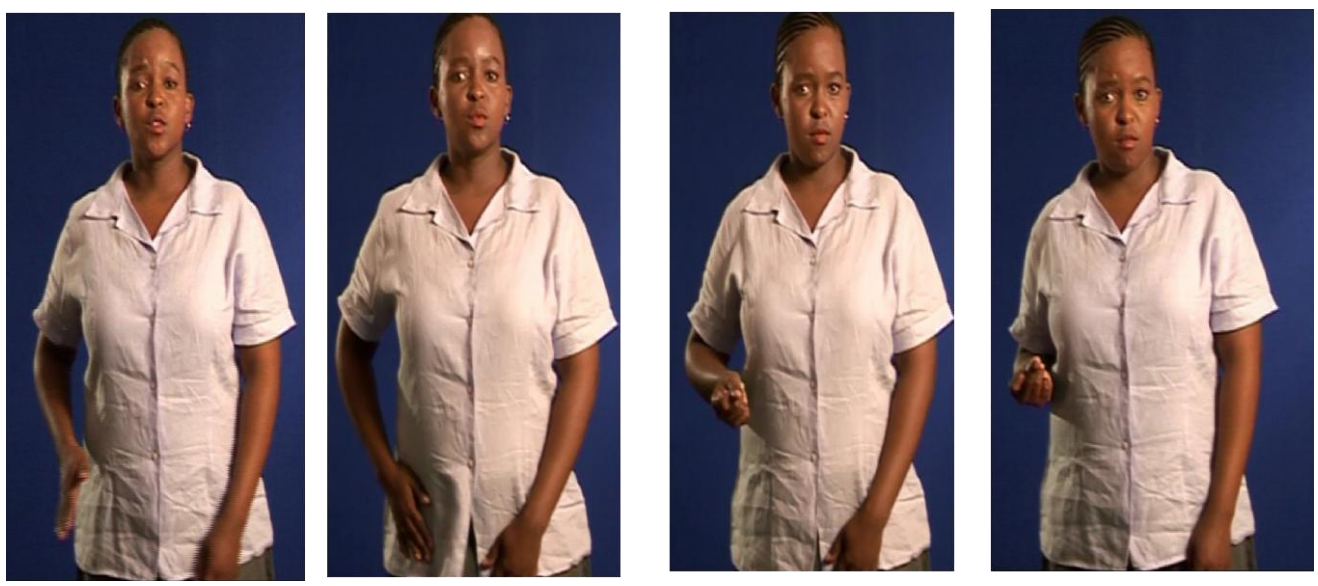

Figure 6: The disyllabic sign DOG (SLED 2006)

Our finding that certain features of a sign syllable may not be specified is not unprecedented in phonological research. Van der Kooij (2002) has found that in Dutch Sign Language, some features of movements are underspecified.

If SASL syllables have the potential to be onsetless, the next point of investigation is to determine whether they can be codaless. What would this mean? An empty coda position would have no specified handshape or location features following a movement, in much the same way that a syllable beginning from the resting position is analysed as an onsetless syllable. Do such signs exist? The apparent answer for SASL is no, as far as syllables involving path movement are concerned. However, it should be noted that not all movements are considered to be syllable peaks - certain movements are considered transitional. Transitional movements are used when the hand needs to move from one meaningful location to another (Johnson and Liddell 2011; Geraci 2009; Sandler and Lillo-Martin 2006). Meaningful movements and transitional movements can be distinguished by velocity: meaningful movements maintain a fairly constant speed, while transitional movements are not as predictable (Jantunen 2013; Johnson and Liddell 2011; Geraci 2009). In the research, transitional movements were not considered to be syllable peaks, thereby eradicating the issue of ambisyllabicity in almost all cases.

There is one class of sign syllables that consist of a nucleus only, with no onset or coda. In these syllables, there is no path movement, meaning that the hand does not move from one location to another during the articulation of the syllable. Instead, a local or secondary movement forms the nucleus of the syllable, meaning that the hand remains at the same location and there are no holds before or after the movement that could constitute an onset or a coda. An example of such a syllable would be the monosyllabic sign WHEN, as illustrated in Figure 7. 

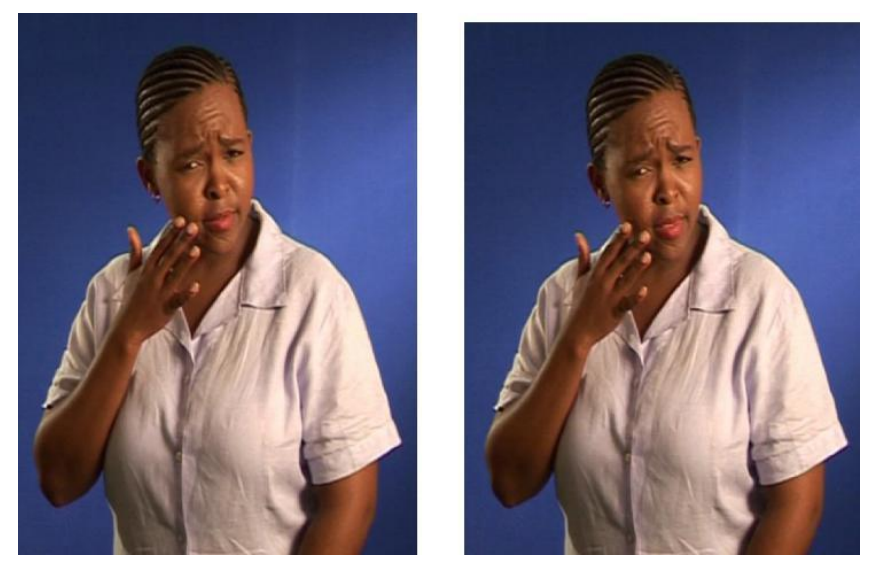

Figure 7: WHEN (SLED 2006). The movement in this sign is a finger wiggle against the cheek.

In our data, there are no instances of signs in which path movement takes place where either the handshape or the location of a coda is unspecified. Thus, it seems that in SASL syllables with path movement, both handshape and location must always be specified at the coda position.

This points to a surprising conclusion: SASL appears to be a language that requires codas in syllables by default. This phenomenon has been confirmed beyond our dictionary data through the assistance of our informants. The two SASL signers we consulted could not provide any examples from their vocabularies of codaless syllables with path movement. This points to the following principle:

\section{Obligatory Coda Requirement}

If a syllable contains path movement, it cannot be codaless.

Therefore, we take as our basic assumption that a normal syllable in SASL consists of an optional onset (which may be underspecified for some features); a mandatory nucleus; and a mandatory coda with both location and handshape specified, which is mandatory for all syllables containing path movement. This is illustrated in Figure 8, with mandatory parts of the syllable underlined, and those that may be absent in parentheses.

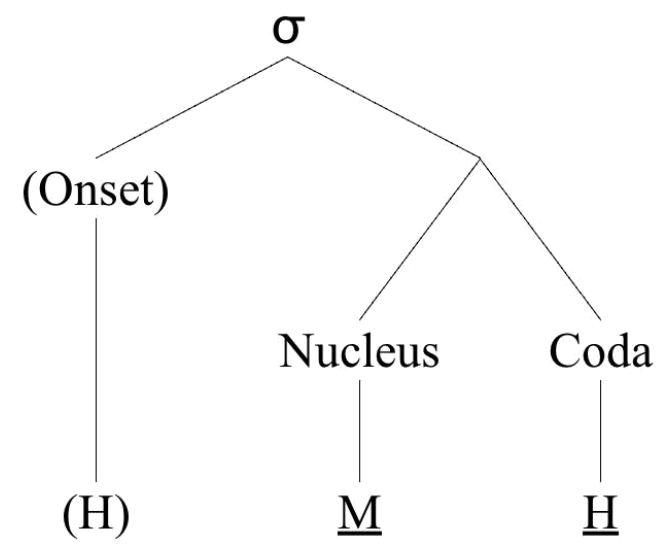

Figure 8: The structure of a syllable in SASL 
The potential for SASL signs to be onsetless was confirmed by both informants during the interview process, using the procedure outlined in section 3.

A potential argument against our analysis of SASL syllable structure is that some may see the movement towards the coda location in signs like YEAR, DANGEROUS, COW, SOUR, OWL, and ORANGE as merely transitional and thus not part of the phonological structure of the sign. However, our informants confirmed that this was not the case in further interviews. These interviews verified that the movements illustrated in Figures 3 and 5 are compulsory for syllables to be considered well-formed, and movement change affects meaning. This is especially relevant in the case of a sign like YEAR, which requires a circular movement to be well-formed. This proves that an onsetless syllable is possible in SASL, despite arguments to the contrary.

\section{Frameworks for analysis}

The general featural framework we assume is based on Brentari's Prosodic Model (1998). There are a large number of models that aim to represent the phonological structure of sign languages. Although the Movement-Hold Model (Liddell and Johnson 1989; Johnson and Liddell 2010) was a forerunner in considering the sequential nature of signs, the model contains many redundancies that make it more difficult to identify phonological patterns (Sandler and Lillo-Martin 2006). This is shown in SASL repeated signs, for instance. Additionally, the Movement-Hold Model contains less description of the hand's characteristics than the Hand Tier Model (Corina and Sandler 1993; Sandler 1989). However, the Hand Tier Model does not accurately represent handshapes that do not move (Brentari 1998). This means that the model cannot account for signs like DEAD (Figure 9), where the handshape and location are the same in onset and coda, but differ in orientation. Additionally, the model does not treat asymmetrical signs as possessing different features, as it considers all handshapes to have the same features. The Prosodic Model (Brentari 1998) combines the sequential and dynamic nature of the Movement-Hold Model and the intricate handshape representation of the Hand Tier Model, making it an ideal phonological framework for describing phonological rules applying to SASL syllables.
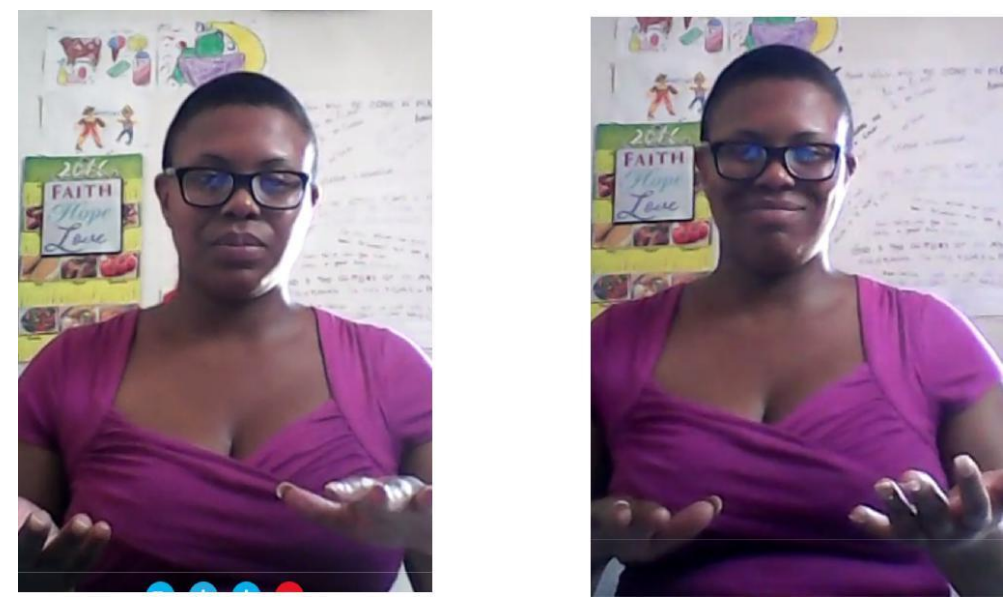

Figure 9: DEAD 
The Prosodic Model has a hierarchical structure that divides features into two overarching groups: Inherent Features (IF) and Prosodic Features (PF). The structure of the Prosodic Model is depicted in Figure 10. The IF branch of the model describes the static elements of the sign, including handshape, setting, and orientation. The PF branch represents the dynamic aspects of the sign, including movement. These branches interact and depend upon each other for satisfactory articulation. Within these branches exists a head-dependent relationship between the daughter nodes, which can be categorised into primary and secondary features. Primary features define the nature of the feature, and secondary features modify their primary counterparts. Primary features for handshape are the main handshape categorisations, such as $[\mathrm{A}]$ or $[\mathrm{B}]$, often using letters of the fingerspelling alphabet as handshape descriptors. Primary features for location are the main body regions [body], [arm], [H2], and [head]. The secondary features for handshape are [curved], [spread], and [stacked], and the secondary features for location are eight individual settings found in each region.

According to Brentari (1998), every feature node within the Prosodic Model has primary and secondary features - a presupposition that connects with our results (as will be seen in section 6). Thus, it is Brentari's feature theory and feature tree that were used for our coding and analysis.

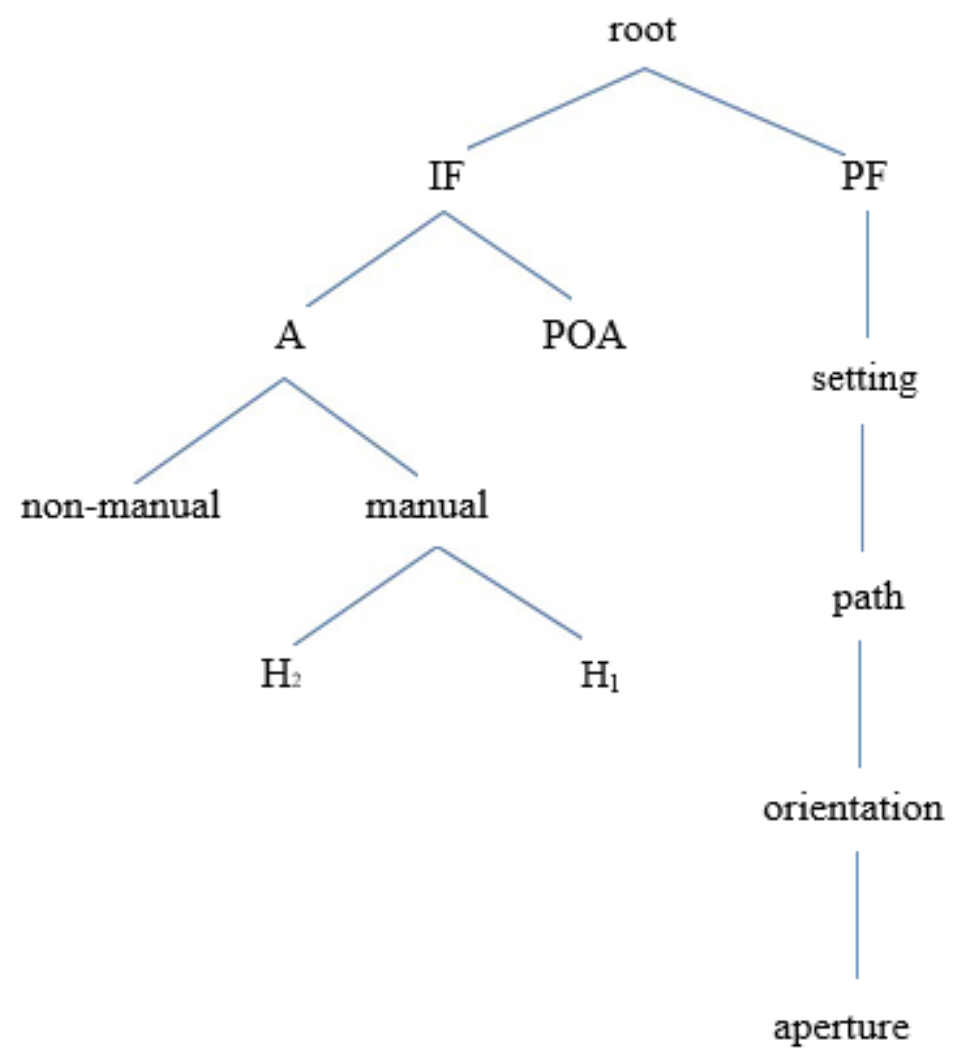

Figure 10: The feature structure of the Prosodic Model (Brentari 1998:26)

However, as we show in section 6, the division between inherent and prosodic features that is assumed is problematic for SASL. In this section, we explain why modifications to the existing feature tree are necessary for SASL and provide a revised feature tree for the language. 


\section{Results}

This section reports on the observation and analysis of patterns discovered in the data for both handshape and location, with particular reference to the primary and secondary features found in the onset and coda. Section 6.1 covers the handshape patterns of both primary and secondary class features. Section 6.2 covers the primary and secondary features of locations.

\subsection{Handshape patterns}

In most SASL syllables, handshapes tend not to change between onset and coda. However, out of a database of 153 signs, around $23 \%$ of signs (i.e. 35 signs) do exhibit primary feature change in handshape, which clearly shows that this is phonologically permissible. We see this in signs such as PLEASE (Figure 11), shown below. The handshape at the onset is different from the handshape in the coda position: the handshape [5] becomes $[\AA ̊]$ at the coda position.
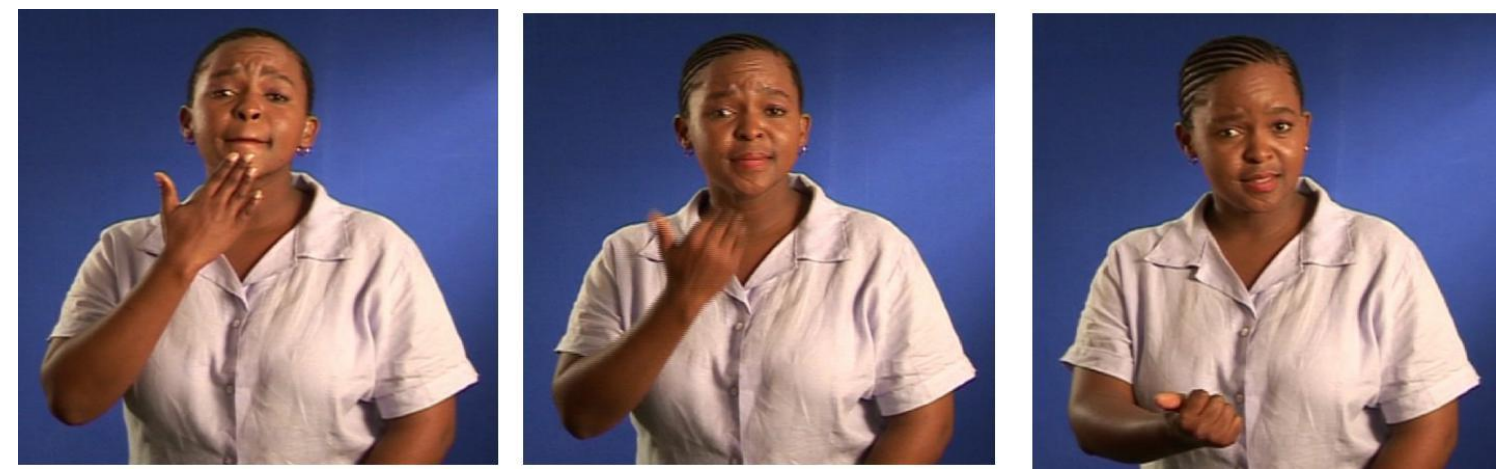

Figure 11: PLEASE (SLED 2006)

Sandler and Lillo-Martin (2001) mention a constraint which disprefers changing from one major handshape to another in the production of a sign. However, this is clearly not an exceptionless restriction, as certain American Sign Language (ASL) signs also show a change of handshape within the morpheme and within the syllable. While this constraint pertains to morphemes and not syllables, it parallels a phonological pattern noticed in SASL syllables.

In signs that exhibit a change in handshape, there is a robust pattern in the handshapes selected in the coda position: changes only ever target a limited set of handshapes. As Table 1 shows, the major class handshapes frequently changed to in the coda position are [1], [5], [A], $[\AA]$, and $[\mathrm{S}]$. What stands out about this class of handshapes is that they show almost complete overlap with the class of unmarked handshapes, [B], [A], [S], [C], [O], [1], [5], which are used by the non-dominant hand in asymmetrical two-handed signs (Brentari 1998; Sandler and Lillo-Martin 2006; Morgan and Mayberry 2012). In this table and in others in this article, grey shading is used to indicate combinations that are unattested in our data. 
Table 1: Onset-coda handshape combinations in our data. The totals at the end of the table indicate the total frequency of changes to each handshape in our data. "Thm" refers to "thumb".

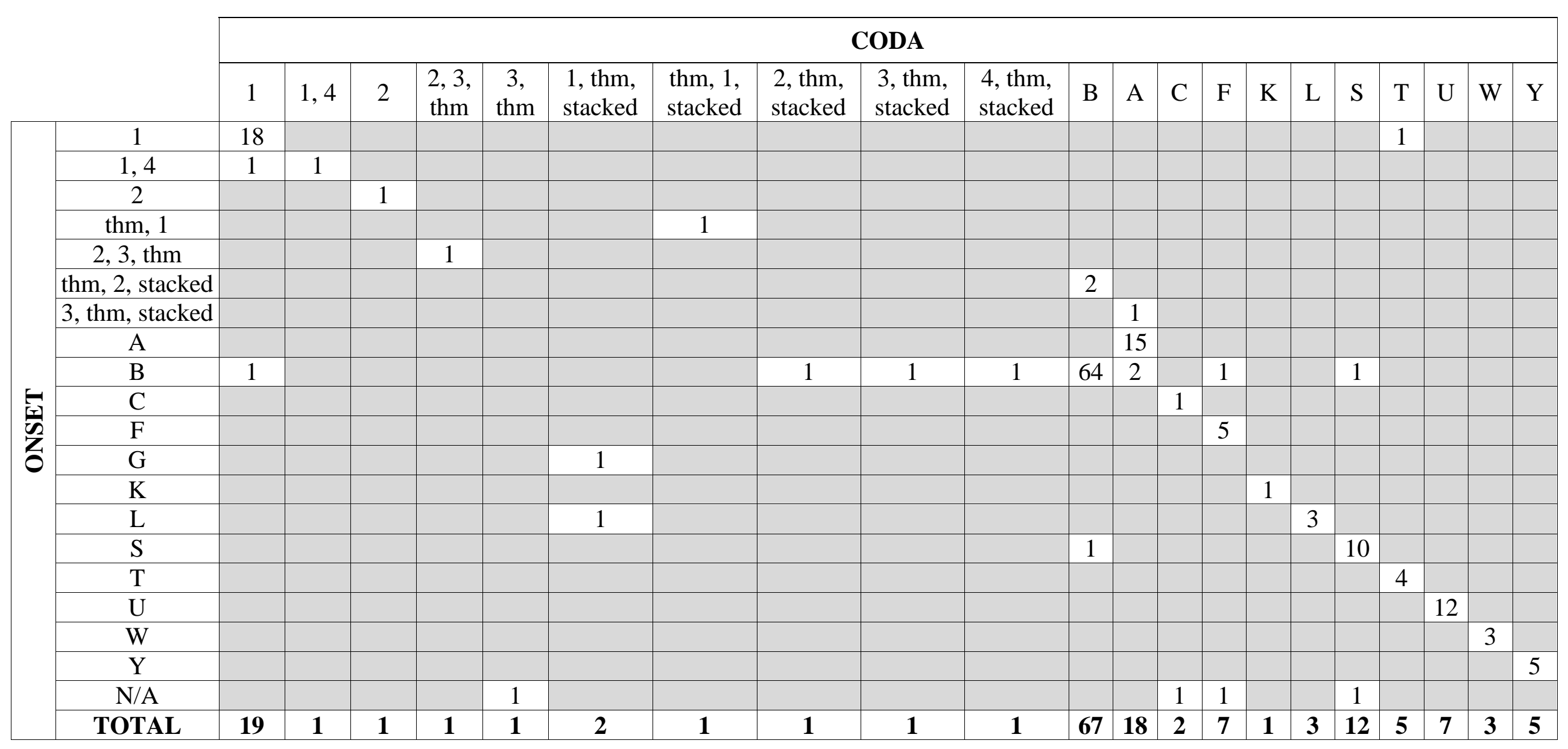


In particular, the most frequent type of handshape change is changes to [5], comprising $28.57 \%$ of all handshape changes, a large percentage given the number of handshape major class features. There may be a number of reasons for this, the first being that certain variations of [5] are the most natural shape that the hand can take physiologically, as it is the 'at rest' handshape of an open hand (Brentari 1998:104). As such, it may be favoured on natural phonetic grounds. Another potential reason is that, of the unmarked handshapes in twohanded signs, [5] is the foremost choice for the non-dominant hand. The two-handed signs in our data that change to a variant of [5] have all been symmetrical (that is, both hands have the same handshape), as shown by PLAY in Figure 12. In this figure, the second and fourth frames depict syllable codas in which the [5] handshape is used.
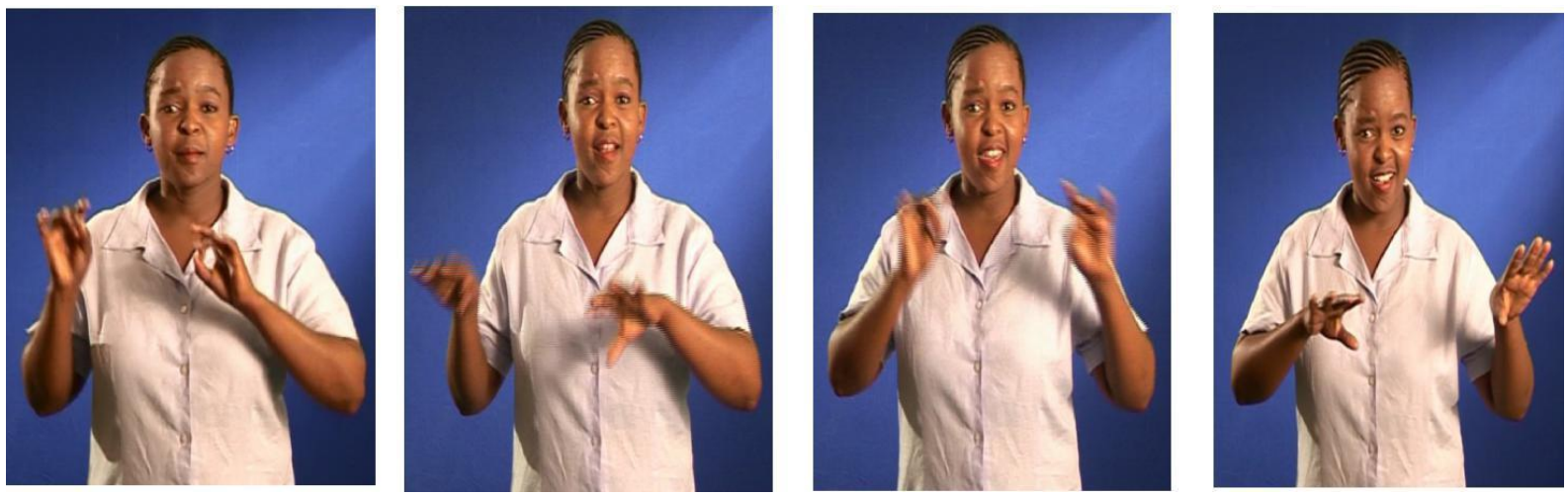

Figure 12: One variant of PLAY (SLED 2006)

Our SASL data provide substantial support for a constraint on handshape change adapted from Sandler and Lillo-Martin (2006).

\section{Revised Handshape Change Constraint}

If there is an instance of handshape change during a syllable's production, the coda will have $[\mathrm{A}],[\mathrm{S}]$ or $[\mathrm{B}]$ as its major feature. The selected fingers will remain constant from onset to coda.

This constraint also prohibits a change of fingers selected in a syllable (Sandler and LilloMartin 2006). According to this constraint, the fingers that are selected for the syllable may change their positioning, but the fingers themselves must stay the same. In short, handshape change is the consequence of selected fingers adjusting during a sign's articulation (Sandler and Lillo-Martin 2006). For example, in signs that change to [5], it can be argued that certain fingers are selected and start in a bent or curved position, flexing to join the other unselected fingers.

One of the exceptions to the Revised Handshape Change Constraint is the sign MONDAY, which is represented as a feature tree in Figure 14. The thumb and index finger are the fingers that move, and are thus the selected fingers. The syllable depicted in Figure 13 is repeated at least once in order for the sign to be considered well-formed. However, the handshape specified at the coda position is $[\mathrm{F}]$, violating the Revised Handshape Change Constraint. In fact, MONDAY, TUESDAY, WEDNESDAY, and THURSDAY all violate the Revised Handshape Change Constraint, meaning that this constraint cannot account for all syllables in SASL, but is rather a tendency in SASL phonology. 

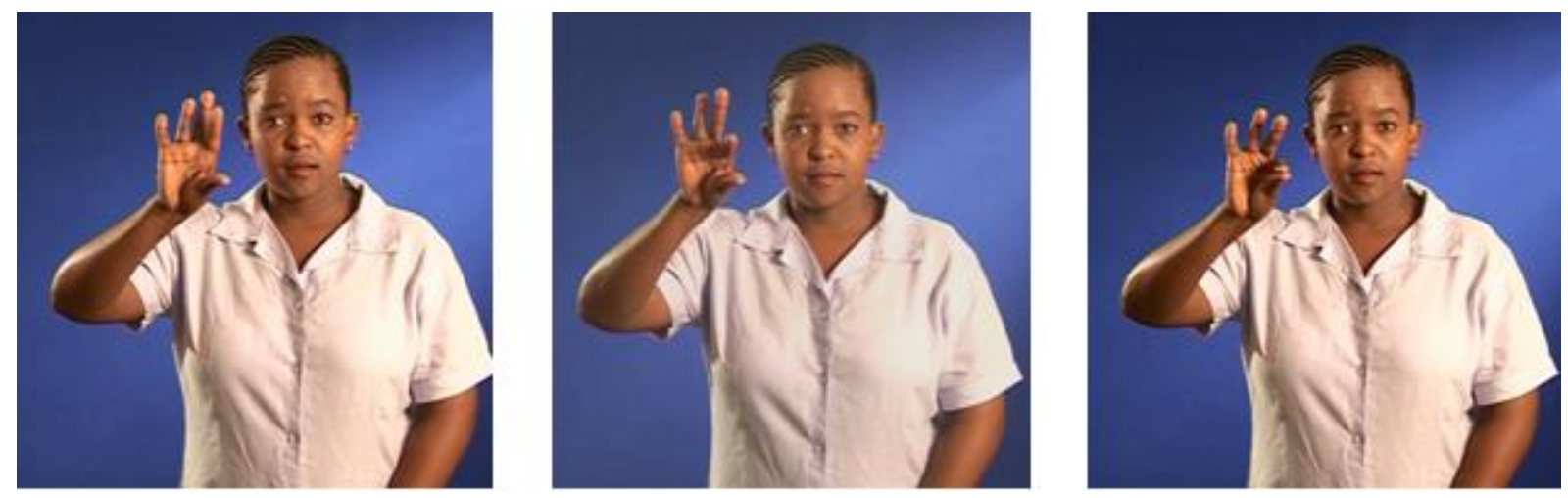

Figure 13: MONDAY (SLED 2006)

\section{MONDAY}

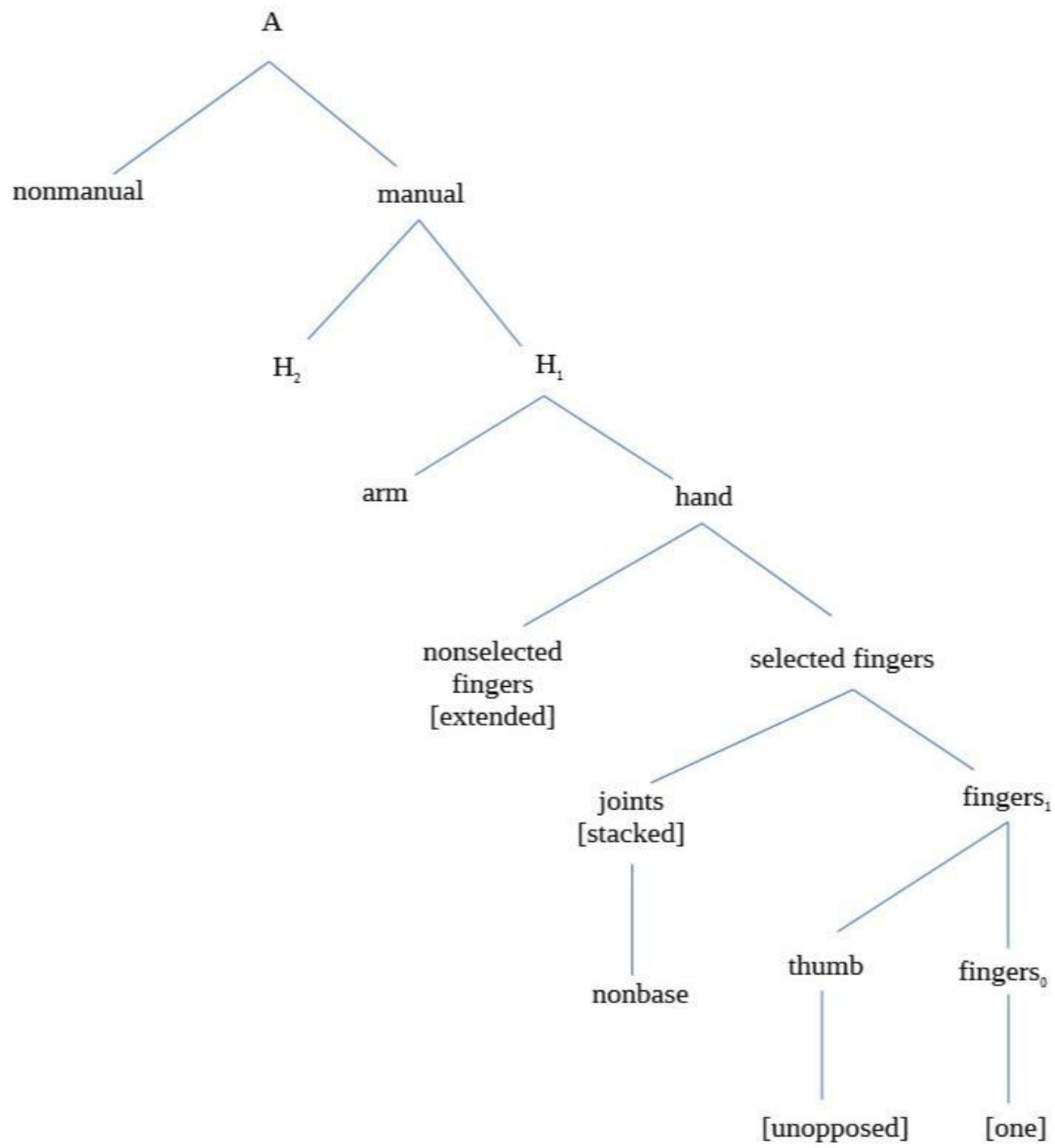

Figure 14: The feature organisation for MONDAY, showing how the selected fingers are featured

Rules and principles that support the argument that selected fingers remain unchanged across the syllable are the Unselected Fingers Redundancy Rule (Corina 1993) and the Maximise 
Finger Contrast (Redundancy Rule) (Brentari 1998), which both state that the unselected fingers assume the opposite position to the selected fingers. The selected fingers are the ones that move to create different handshapes. It is worth noting that the handshapes formed by the selected fingers are the unmarked handshapes of the non-dominant hand, with [5] being the most frequent. Therefore, it can be said that should the constraints on selected fingers apply, the least marked position of non-selected fingers is [flexed]. This is reiterated in the Revised Handshape Change Constraint, as the changes to the unmarked handshapes in the coda position are the result of the selected fingers undergoing change.

Selected fingers do not only change position: they can also change their joint specifications without changing their original positioning. This is done through the secondary class features of [spread]; [curved]; [curved], [spread]; and [stacked]. Table 2 provides the possible joint combinations observed in our SASL data:

Table 2: Joint specification combinations between onsets and codas in our SASL data

\begin{tabular}{|c|c|c|c|c|c|}
\hline & \multicolumn{5}{|c|}{ CODA } \\
\hline \multirow{5}{*}{$\begin{array}{l}\mathbf{O} \\
\mathbf{N} \\
\mathbf{S} \\
\mathbf{E} \\
\mathbf{T}\end{array}$} & & [curved] & $\begin{array}{l}\text { [curved], } \\
\text { [spread] }\end{array}$ & [spread] & [stacked] \\
\hline & [curved] & 11 & 1 & & \\
\hline & $\begin{array}{l}\text { [curved], } \\
\text { [spread] }\end{array}$ & 1 & 7 & & \\
\hline & [spread] & & 1 & 12 & 3 \\
\hline & [stacked] & & & 2 & 2 \\
\hline
\end{tabular}

As shown above, there is a tendency for secondary features to remain constant from onset to coda: most signs do not change the joint specifications of selected fingers. However, when there is a change, a sign with [curved] at the onset will only allow [curved] or [curved], [spread] at the coda. Signs with [spread] at the onset will only allow [curved], [spread] at the coda. If the onset is [curved], the coda will never be [spread], and if the onset is [spread], the coda will never be [curved]. In fact, a variant of [curved] cannot be specified at the coda unless a variant of [curved] is specified at the onset. This is captured in the following constraint:

\section{[curved] Feature Constraint}

If the onset has the feature [curved], this feature must also appear in the coda.

The secondary feature [stacked] frequently patterns with [spread], as in PLAY (Figure 12) and WEDNESDAY (Figure 15). In WEDNESDAY, the syllable depicted in Figure 15 is repeated at least once in order for the sign to be considered well-formed. 

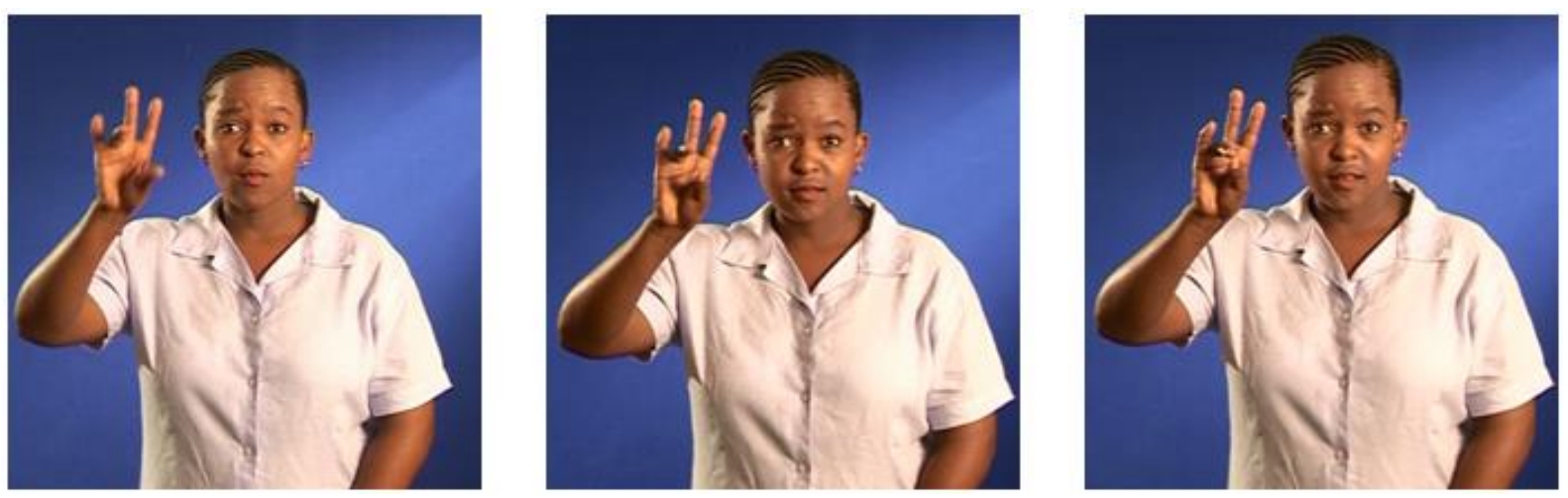

Figure 15: WEDNESDAY (SLED 2006)

To summarise, we find robust evidence for coda restrictions on handshape in SASL. While most SASL syllables retain the same handshape specification from onset to coda, some signs change handshape. Among those signs involving handshape change, a restricted set of possibilities occurs in coda position: the range of handshape contrasts found in onset position is collapsed to just the handshapes [1], [5], [A], [̊], and [S]. Moreover, this particular class of possibilities is essentially a subset of the basic handshapes found on the non-dominant hand.

We also find evidence for constraints on possible changes of selected-finger settings: certain kinds of changes are permitted, but others are not. If a syllable onset is [spread], the coda may be [spread]; [curved], [spread] or, less commonly, [stacked], but it may not be [curved]. Based on our data, it is most common for a syllable to have the same selected-finger setting in coda and onset. However, among those that do change setting, not all possible combinations are attested.

In SASL, codas seem to follow one of two patterns: either they have the same feature specifications as the onset of the same syllable, or they diverge to a restricted set of possibilities. That is, codas either have unmarked specifications, or they agree with the onset of the same syllable. Both of these patterns occur in spoken language phonology. In Obolo, for example, syllables are subject to nasal agreement (see Bennett 2015:179 and references therein). Both [+nasal] and [-nasal] coda consonants are possible in Obolo, but if a syllable has a [+nasal] onset then its coda must also be [+nasal]. The feature [curved] in SASL appears to behave in the same way: if a syllable's onset is [curved], then its coda must also be [curved]. Where the onset-coda co-occurrence patterns of SASL deviate from these kinds of agreement, there appears to be neutralisation. We also see this in the patterning of basic handshapes: apart from a few counterexamples, the handshape of a coda in SASL either (a) agrees with the handshape specification of the onset, or (b) is one of the unmarked handshapes [1], [5], [A], [̊], [S]. Taken together, these patterns provide clear evidence that the phonology of SASL regulates codas in ways that are cross-linguistically familiar from previous literature. 


\subsection{Location patterns}

Sandler (1989) proposed the Revised Place Constraint, which states:

Revised Place Constraint

There can be only one POA per morpheme.

The Revised Place Constraint forbids region change within a morpheme, but still allows region change within syllables containing more than one morpheme, as in certain compounds in some sign languages (see Geraci 2009). Since we are concerned solely with the phonological description of SASL and not its morphology, we deliberately leave unanswered the question of whether the Revised Place Constraint applies to SASL. However, a substantial number of signs in SASL do show changes in body region within the syllable, as shown in Table 3. Twelve percent of our data consists of signs where the body region of the coda location differs from that of the onset.

Table 3: Distribution of onsets and codas among the primary location features in our data

\begin{tabular}{|c|c|c|c|c|c|c|}
\hline & \multicolumn{6}{|c|}{ CODA } \\
\hline \multirow{6}{*}{$\begin{array}{l}\mathbf{O} \\
\mathbf{N} \\
\mathbf{S} \\
\mathbf{E} \\
\mathbf{T}\end{array}$} & & [arm] & [body] & [H2] & [head] & N/A \\
\hline & [arm] & 4 & & & & \\
\hline & [body] & & 13 & & & \\
\hline & {$[\mathrm{H} 2]$} & & & 16 & & \\
\hline & [head] & & 1 & & 23 & 1 \\
\hline & N/A & 3 & 4 & 6 & 8 & \\
\hline
\end{tabular}

From our data, it seems that the majority of syllables in SASL begin and end at the same location, or prefer a setting change so that the sign stays within the major body region in which it begins. This is seen especially in the [arm] location, as all signs in the database with [arm] in the onset remain within that body region.

However, signs beginning in all body regions except [arm] may move to at least one other body region. As Table 3 shows, the most frequent body regions in general are the trunk area (referred to as [body], 47\%) and the non-dominant hand (referred to as [H2], 25\%), making up more than half of the dictionary. This is interesting, as not only are they the most common body regions, but both [body] and [H2] are the preferred coda locations in region change. Signs that include region change to [body] are SICK (Figure 16), SON (Figure 17), and DAUGHTER (Figure 18). The latter two signs did not appear in the dictionary data but were used as examples of region change in discussion with our informants. SON moves from [ipsi], [head] in the onset position to [contra], [body] in the coda position. DAUGHTER undergoes the same body region movement with a different handshape. 

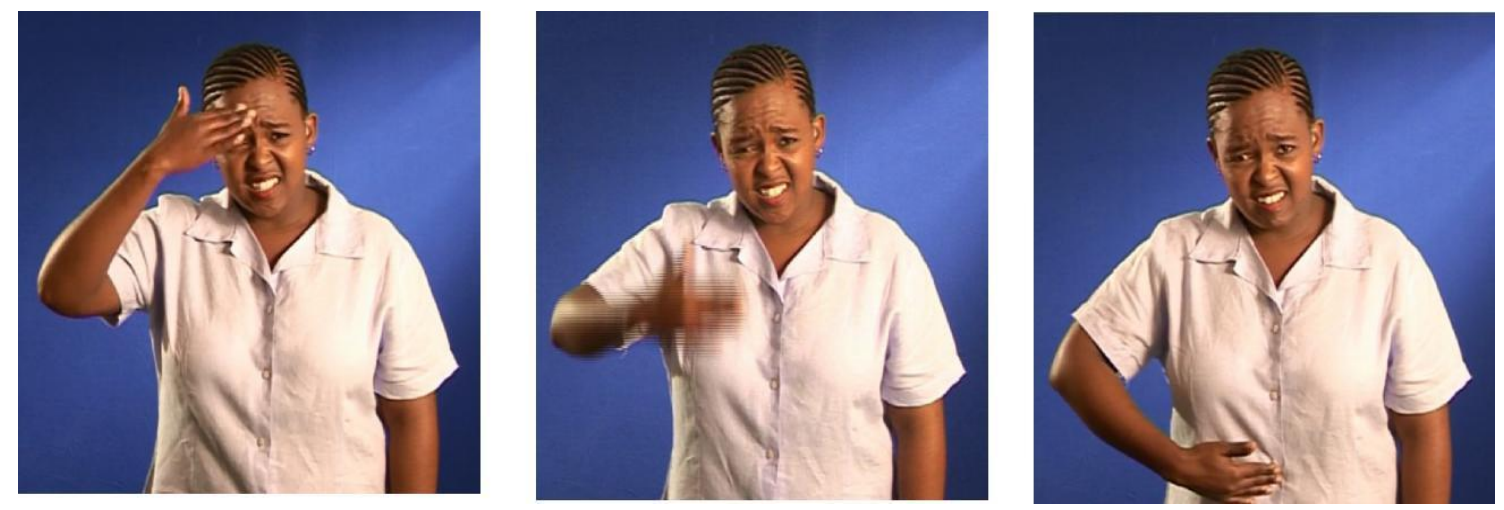

Figure 16: SICK (SLED 2006)
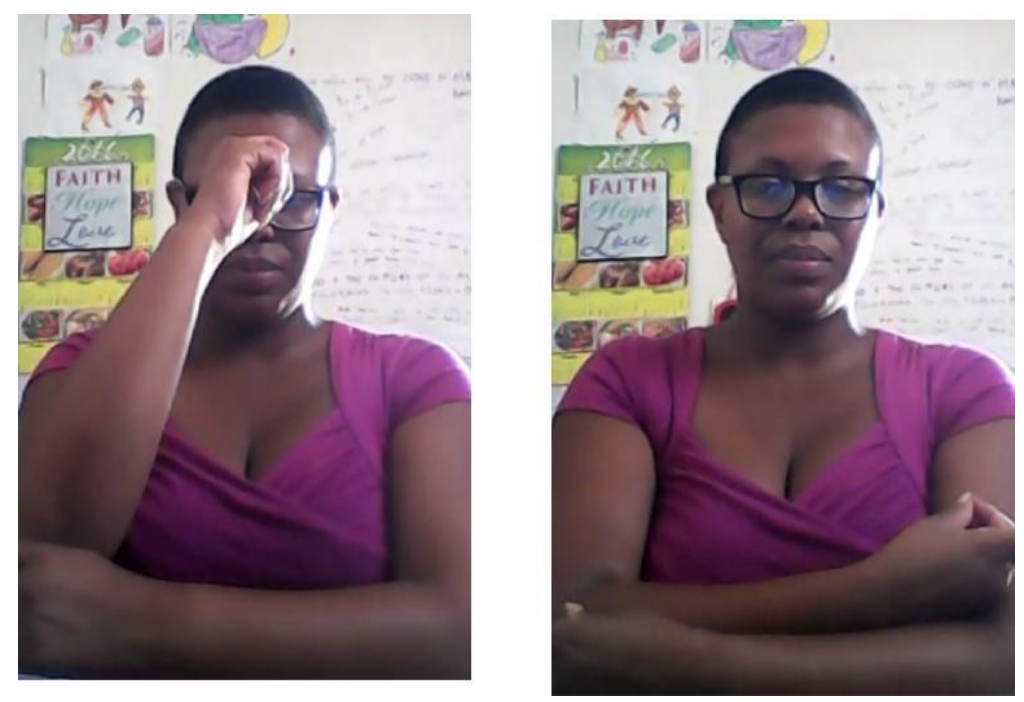

\section{Figure 17: SON}
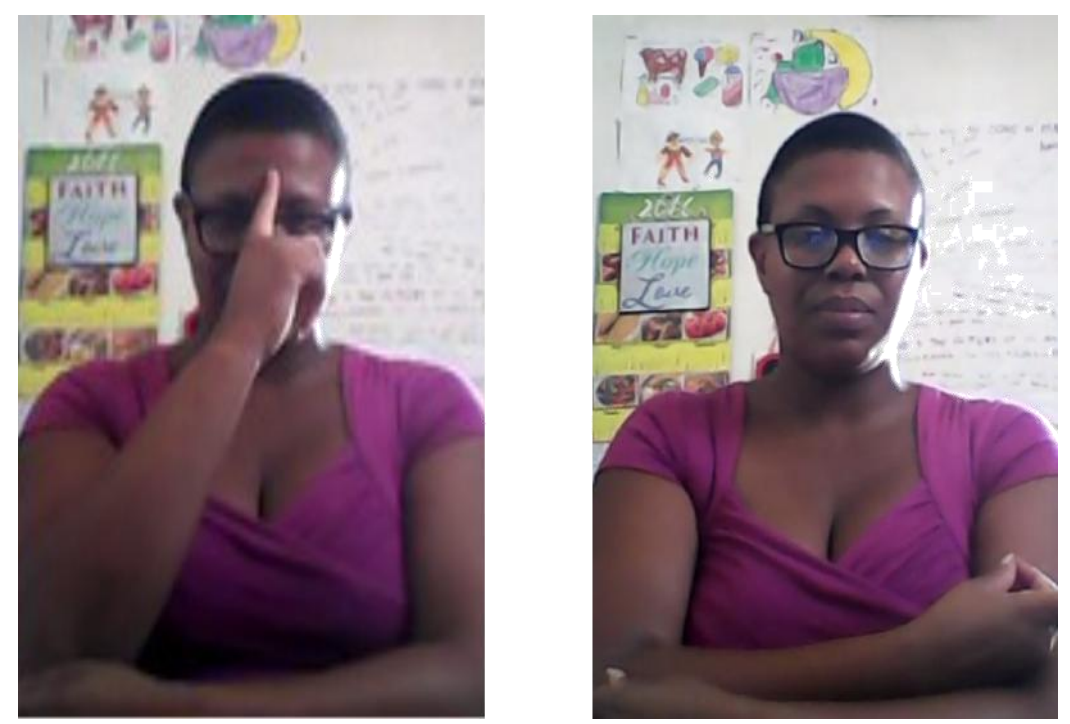

Figure 18: DAUGHTER 
We note that the patterning of region change parallels the patterning of handshape changes discussed above. The generalisation can be stated as in (10).

Coda Location Constraint

The POA may change during the production of a syllable, provided that the major body region changes to either [body] or [H2].

This parallels the handshape changes exactly: either the onset and coda of a SASL syllable agree in location, or the coda's location is restricted to a limited subset of the possibilities found in onsets. One of our informants confirmed that region change went from [head] to [body] and not the other way around, as well as confirming that those were the only region changes she was aware of.

The generalisation evident here is quite similar to what we observed previously with handshape: the coda's location is either in the same region as the onset (agreement), or shifts to a restricted subset of possible values (neutralisation). In the domain of location, this reduction to less marked values follows a pattern of centralisation towards the body (cf. Friedman 1976). In SASL, a coda location will tend to be closer to the centre of the signer's torso area than the onset.

A region change that could provide an exception to this constraint is found in the signs MOUNTAIN (Figure 19) and BEDSHEET (Figure 20), which were raised as counterexamples by our informants. In these signs, the onset is the shoulder (a setting in the [body] region) and the coda is the wrist (a setting in the [arm] region). However, these signs are formed from classifiers, as the arm in this case represents the earth (MOUNTAIN) or the bed (BEDSHEET), which is a possible classifier. As pointed out in section 3, classifiers tend to follow a different set of phonological rules to other signs, and so this may explain why these signs are exceptions to the Coda Location Constraint.
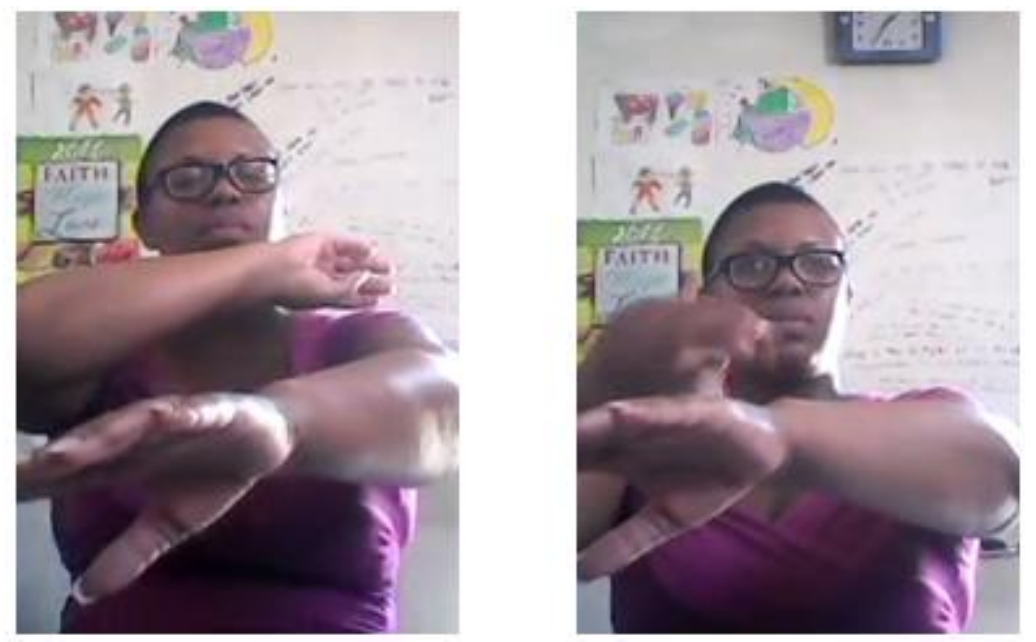

Figure 19: MOUNTAIN 

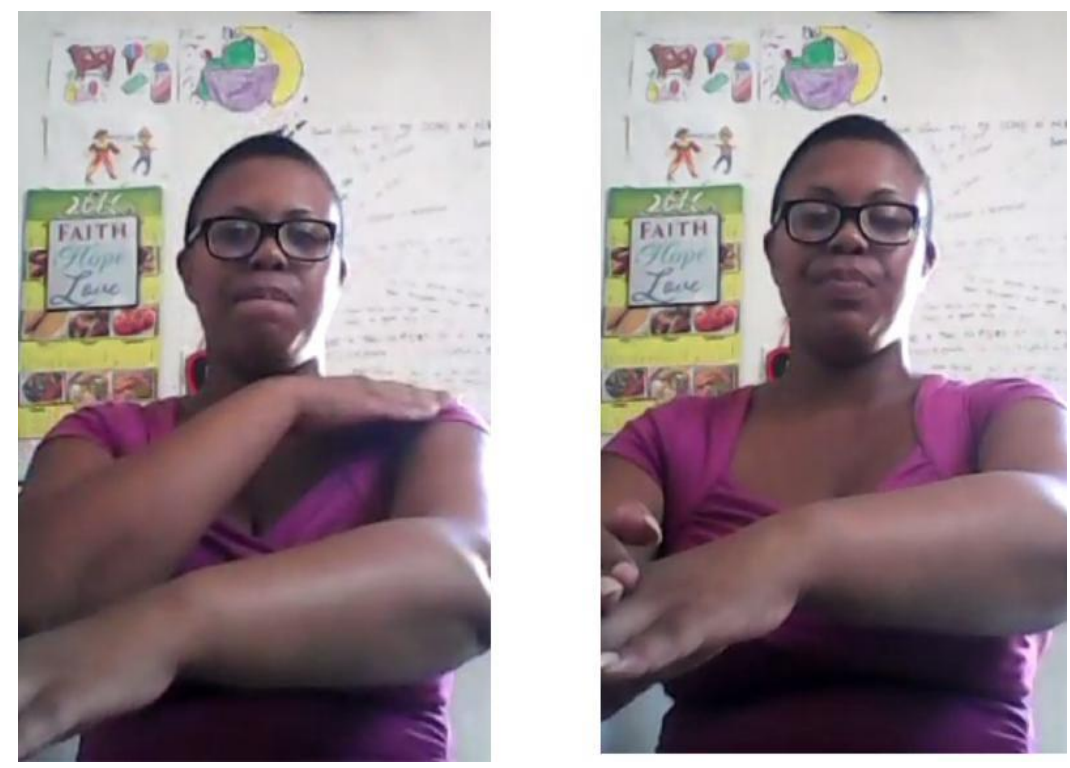

Figure 20: BEDSHEET

\subsection{Theoretical implications}

Signs that change their major body region pose a problem for the Prosodic Model (Brentari 1998). In this model, as illustrated in Figure 10, there is a clear separation between the POA features that specify body regions and the setting change (setting $\Delta$ ) node that specifies location changes within the same region. The Revised Place Constraint forbids region change within a morpheme, but still allows region change within syllables containing more than one morpheme, as in certain compounds in some sign languages (see Geraci 2009). Since we are concerned solely with the phonological description of SASL and not its morphology, we deliberately leave unanswered the question of whether the Revised Place Constraint applies to SASL. However, our data above clearly show that SASL in fact allows for more than one POA within a syllable, with $12 \%$ of our dataset exhibiting change in POA.

Since signs with major region change are attested in SASL, the Prosodic Model must be modified if it is to describe the phonology of SASL adequately. We suggest that the distinction between IF and PF should not bisect place and setting specifications. Our proposal is that the POA and setting features, rather than straddling these two categories, should form their own node of the feature tree, linked to the PF structure of the tree. This is illustrated in Figure 21. Each POA or body region is divided into eight settings (Brentari 1998), so it becomes hierarchically necessary to place 'settings' as a daughter of the POA node. Additionally, planes of articulation were dominated by the POA branch in its original position. If we are to move the POA branch so it can be dominated by the PF branch, it stands to reason that all nodes originally dominated by the POA branch must move with it. 


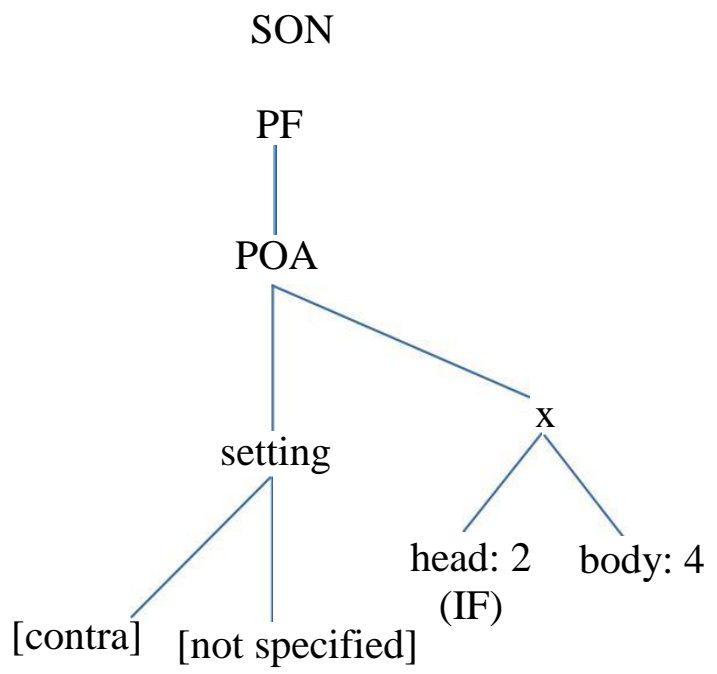

(IF)

Figure 21: Adapted Prosodic Model representation of SON, using the revised feature tree to illustrate the movement from the side of the head to the chest

There is some debate about the origins of the signs SON, DAUGHTER, and SICK; three signs that exhibit region change in our data. It is possible that SON could originally have come from a compound (BOY-MY), with DAUGHTER being a derivative of that. Additionally, SICK could have originated from the two places one most commonly feels some form of sickness (e.g. HEAD-SORE + STOMACH-SORE). If they did derive from compounds, these signs would have comprised two separate morphemes, and thus would have conformed to the Revised Place Constraint. Our informants could neither confirm nor deny the possibility of these signs originating from compounds, but it is confirmed that the signs, as they are used now, are monosyllabic. The nucleus in each syllable in these signs is a movement from one region to another, which means that the onset of a syllable is articulated in a different region to the coda of that same syllable. However, as seen in Figure 10, the signer's body region belongs to the IF branch in the original structure of the Prosodic Model. As stipulated earlier, the IF branch dominates articulatory features that are underlyingly unchanging throughout the syllable's articulation. However, if the POA branch remains dominated by the IF branch, the Prosodic Model cannot accurately account for these signs. As such, the model must be adjusted to allow for the possibility of a change of body region within a single syllable, as we have proposed. This makes POA a dynamic articulatory feature, which as such should be dominated by the PF branch.

While it is true that SON, DAUGHTER, BEDSHEET, and MOUNTAIN are a few exceptional signs that were not present in the initial dataset, these signs exhibit region change, along with a substantial percentage of our data. It is thus necessary for a phonological model to accommodate these signs if it is to describe SASL accurately. It is also possible that more signs with region change exist - a possibility that could form the basis of further research. Thus, exploration and description of these signs is necessary, making the adjustments to the Prosodic Model necessary as well. 


\section{Conclusion}

From our data, it is quite evident that SASL, a rich and understudied language, possesses many interesting phonological characteristics, each clearly deserving much more focused research. We summarise our main findings as follows:

Summary of major findings on SASL codas

a. Constraints on SASL syllable codas are based on the onset and whether or not the sign allows the changing of features between onset and coda: most of the constraints involve some form of featural agreement.

b. When the handshape changes, the preferred coda handshape is one of the unmarked handshapes, most commonly a variant of [5]. Where a coda does not agree in handshape with the onset, it can be seen as neutralisation to a limited subset of unmarked specifications.

c. When the secondary features of a handshape change from onset to coda, there are certain features that are not allowed in coda position and others that are only permitted if they occur together with another feature (i.e. [spread], [curved]).

d. In SASL, major body location change from onset to coda is attested. When changes in major body location occur, the coda can differ from the onset only if it is [body] or [H2].

Some of these findings are consistent with previous work on other signed languages, as well as spoken languages. Neutralisation and agreement, for example, are well-established phenomena in spoken language phonology; the set of handshapes found in codas also appears to be closely affiliated with the set of handshapes permitted for the non-dominant hand in asymmetric two-handed signs in other signed languages. However, we do find that Brentari's (1998) Prosodic Model is not entirely sufficient to represent all signs of SASL. Specifically, the idea that SASL signs can involve changes of major body region is at odds with the Prosodic Model's analysis of POA as a fundamentally inherent feature. Our proposed revision to the model is to represent major POA and its dependent settings in a node that is not solely dependent on the IF branch of the tree.

Additionally, we also note that SASL appears to allow onsetless syllables, but requires codas in all but a small class of syllables. At first glance, this seems like the exact opposite of basic syllable structure patterns in spoken languages, where codas may be forbidden, but are never required. We are therefore left with a somewhat puzzling combination of conclusions. On the one hand, there is evidence that SASL employs restrictions on the coda position that are not enforced for onsets; but, on the other hand, the language seems to forbid the absence of codas in most cases. This required-but-restricted status of codas might be interpreted as evidence that the relation between syllable margins and nuclei is the reverse of the norm for spoken languages - an intriguing prospect that we leave as a question for future work to explore more fully. 
Finally, we note that while SASL presents clear evidence of asymmetries between onsets and codas, it does not show restrictions on codas in precisely the same fashion familiar from spoken language phonology. Specifically, the kinds of coda restrictions evidenced here are not requirements that all codas are drawn from a restricted subset of less-marked elements (on par, for instance, with prohibitions against voiced obstruents, etc.). Instead, what we find is that markedness-based restrictions hold only for those codas that are non-identical to onsets. Since restrictions of this sort involve a dependency between the coda and the onset, it is reasonable to wonder whether they might all be reduced to phonotactic constraints operating over syllables as a whole, without direct reference to codas (à la Van der Kooij and Crasborn 2008). We leave this question for further work to pursue.

\section{References}

Aarons, D. and R.Z. Morgan. 2003. Classifier predicates and the creation of multiple perspectives in South African Sign Language. Sign Language Studies 3(2): 125-156.

Aarons, D. and L. Reynolds. 2003. South African Sign Language: Changing policies and practice. In L. Monaghan, C. Schmaling, K. Nakamura and G. H. Turner (eds.) Many ways to be Deaf: International variation in Deaf communities. Washington, DC: Gallaudet University Press.

Akach, P., E. Demey, E. Matabane, M. Van Herreweghe and M. Vermeerbergen. 2009. What is South African Sign Language? What is the South African Deaf community? In B. BrockUtne and I. Skattum (eds.) Languages and education in Africa: A comparative and transdisciplinary analysis. Oxford: Symposium. pp. 333-347.

Bennett, W. G. 2015. The phonology of consonants: Harmony, dissimilation, and correspondence. Cambridge: Cambridge University Press.

Blevins, J. 1995. The syllable in phonological theory. In J.A. Goldsmith (ed) The handbook of phonological theory. Malden: Blackwell. pp. 206-244.

Brentari, D. 1998. A prosodic model of sign language phonology. Cambridge, Mass.: MIT Press.

Corina, D. 1993. To branch or not to branch: Underspecification in ASL handshape contours. In G. Coulter (ed.) Current issues in ASL phonology. New York: Academic Press. pp. 63-95.

Corina, D. P. and W. Sandler. 1993. On the nature of phonological structure in sign language. Phonology 10(2): 165-207.

Friedman, L. 1976. Phonology of a soundless language: Phonological structure of the American Sign Language. Doctoral dissertation. California: University of California.

Fudge, E.C. 1999. Syllables. In J. A. Goldsmith (ed.) Phonological theory: The essential readings. Malden: Blackwell. pp. 370-391.

Ganiso, M. and R. Kaschula. 2013. Sign Language: A South African and global perspective. Saarbrücken: Lambert Academic Publishing. 
Geraci, C. 2009. Epenthesis in Italian Sign Language. Sign Language and Linguistics 12(1): 3-51.

Humbert, H. 1995. Phonological segments: Their structure and behavior. Doctoral dissertation. Amsterdam: University of Amsterdam.

Jantunen, T. 2013. Signs and transitions: Do they differ phonetically and does it matter? Sign Language Studies 13(2): 1-44.

Johnson, R. E. and S.K. Liddell. 2010. Toward a phonetic representation of signs: Sequentiality and contrast. Sign Language Studies 11(2): 241-274.

Johnson, R. E. and S.K. Liddell. 2011. A segmental framework for representing signs phonetically. Sign Language Studies 11(3): 408-463.

Kessler, B. and R. Treiman. 1997. Syllable structure and the distribution of phonemes in English syllables. Journal of Memory and Language 37: 295-311.

de Lacy, P. 2006. Markedness: Reduction and preservation in phonology. Cambridge: Cambridge University Press.

Liddell, S. K. 1984. Unrealized-inceptive aspect in American Sign Language: Feature insertion in syllabic frames. Chicago Linguistics Society: Papers from the General Session at the Regional Meeting 20: 257-270.

Liddell, S.K. and R.E. Johnson. 1989. American Sign Language: The phonological base. Sign Language Studies 64: 197-277.

Lombardi, L. 1999. Positional faithfulness and voicing assimilation in Optimality Theory. Natural Language and Linguistic Theory 17: 267-302.

Morgan, H. E. and R.I. Mayberry. 2012. Complexity in two-handed signs in Kenyan Sign Language. Sign Language \& Linguistics 15(1): 147-174.

Morgan, R., M. Glaser and L. Magongwa. 2016. Constructing and rolling out the new South African Sign Language (SASL) curriculum - Reflexive critique. Per Linguam 32(2): 15-29.

Newkirk, D. 1998. On the temporal segmentation of movement in American Sign Language. Sign Language and Linguistics 1(2): 173-211.

Ngwinika, N. 2016. Borrowing in SASL. MA thesis. Johannesburg: University of the Witwatersrand.

Penn, C. 1992. Dictionary of Southern African signs for communicating with the Deaf. Pretoria: Human Sciences Research Council.

Perlmutter, D.M. 1992. Sonority and syllable structure in American Sign Language. Linguistic Inquiry 23(3): 407-442. 
Sandler, W. 1989. Phonological representation of the sign: Linearity and nonlinearity in American Sign Language. Dordrecht: Foris.

Sandler, W. and D. Lillo-Martin. 2001. Natural sign languages. In M. Arnold and J. ReesMiller (eds.) Handbook of linguistics. Malden: Blackwell. pp. 533-562.

Sandler, W. and D. Lillo-Martin. 2006. Sign language and linguistic universals. Cambridge: Cambridge University Press.

Scott, K. 2014. The state of South African Sign Language. Ground Up. Available online: http://www.groundup.org.za/article/state-south-african-sign-language_2287/ (Accessed 22 October 2016).

Schütz, A. J. 1995. All About Hawaiian. Honolulu: University of Hawai'i Press.

Sign Language Education and Development (SLED). 2006. A South African dictionary for families with young Deaf children. Cape Town: Sign Language Education and Development.

Spencer, A. 1996. Phonology: Theory and description. Cambridge: Blackwell Publishing.

Storbeck, C. 2010. South Africa: An overview. American Annals of the Deaf 155(4): 489-490.

Van der Kooij, E. 2002. Phonological categories in Sign Language of the Netherlands: The role of phonetic implementation and iconicity. Doctoral dissertation. Utrecht: LOT.

Van der Kooij, E. and O. Crasborn. 2008. Syllables and the word-prosodic system in Sign Language of the Netherlands. Lingua 118: 1307-1327.

Vermeerbergen, M., M. van Herreweghe, P. Akach and E. Matabane. 2007. Constituent order in Flemish Sign Language (VGT) and South African Sign Language (SASL). Sign Language \& Linguistics 10(1): 25-54.

Wetzels, W. L. and J. Mascaró. 2001. The typology of voicing and devoicing. Language 77(2): 207-244.

Wilbur, R. 2011. Sign syllables. In M. van Oostendorp, C. J. Ewen, E. Hume and K. Rice (eds.) The Blackwell companion to phonology. Malden: Blackwell.

Zec, D. 2007. The syllable. In P. de Lacy (ed.) The Cambridge handbook of phonology. Cambridge: Cambridge University Press. pp. 161-194. 